Universidad de Lima

Escuela de Posgrado

Maestría en Tributación y Política Fiscal

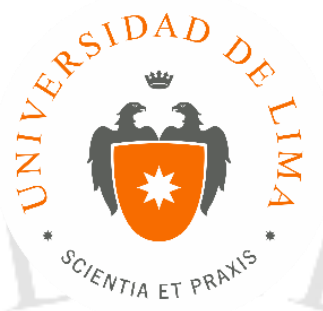

\title{
EL REGIMEN DEL PATENT BOX Y SU POSIBLE IMPLEMENTACIÓN EN EL PERÚ
}

Trabajo de investigación para optar el Grado Académico de Maestro en

Tributación y Política Fiscal

Julissa Milagros Medina Ramos

Código 20152614

Asesor

Fernando Núñez Ciallella

Lima - Perú

Julio de 2017 


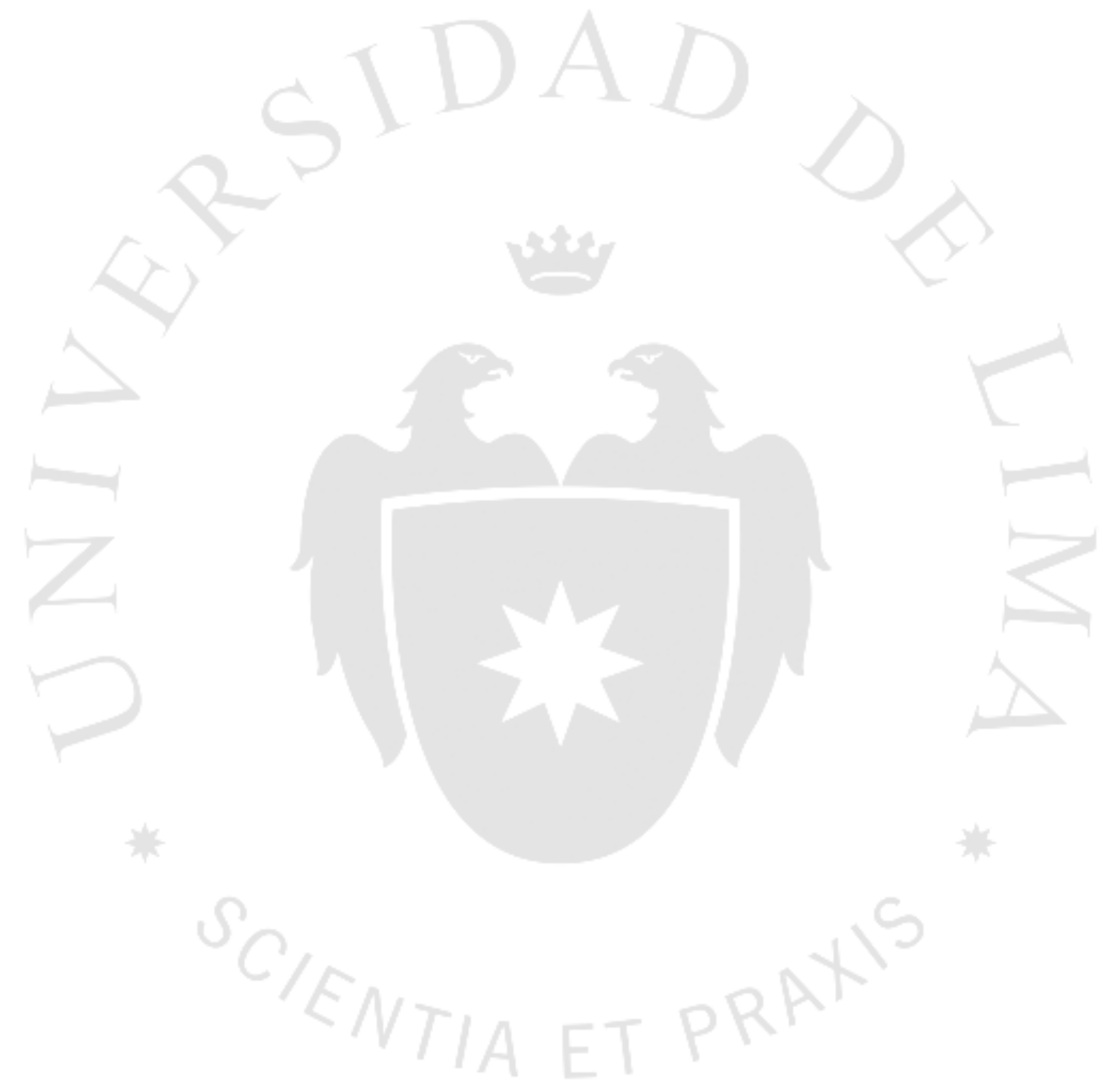




\section{EL REGIMEN DEL PATENT BOX Y SU POSIBLE IMPLEMENTACIÓN EN EL PERÚ}




\section{TABLA DE CONTENIDO}

INTRODUCCIÓN

CAPÍTULO I: ACTIVIDADES DE INVESTIGACIÓN, DESARROLLO E INNOVACIÓN: IMPORTANCIA Y REGULACIÓN .2

1.1 Importancia de las Actividades de Investigación, Desarrollo e Innovación 2

1.2 Régimen Tributario aplicable a las Actividades de Investigación, Desarrollo e Innovación .5

1.2.1 Régimen aplicable hasta el año 2012 ..........................................6

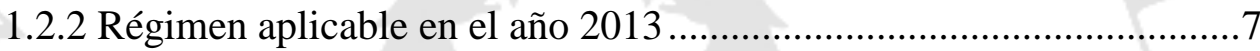

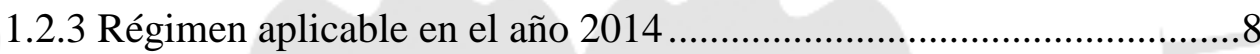

1.2.4 Régimen aplicable aplicable a partir del año 2016 ..........................9

CAPÍTULO II: MARCO CONCEPTUAL DEL PATENT BOX .........................13

2.1. Orígenes y concepto del Patent Box ...................................................13

2.2. Principales Implicancias del Régimen del Patent Box .........................16

2.2.1. Ventajas del Régimen del Patent Box ...........................................16

2.2.2. Desventajas del Régimen del Patent Box.....................................18

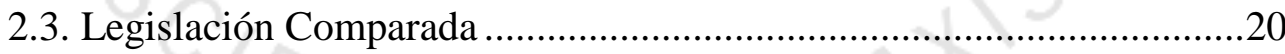

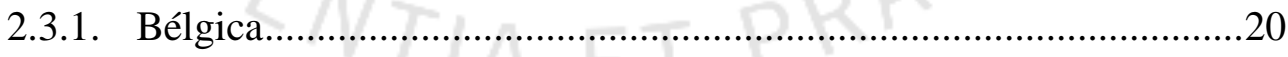

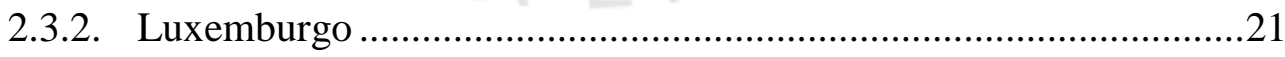

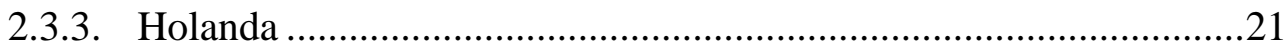

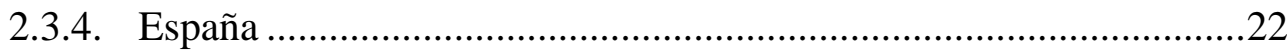

CAPÍTULO III: APLICACIÓN DEL RÉGIMEN DEL PATENT BOX EN EL PERÚ Y SUS POSIBLES IMPLICANCIAS........................................................24

3.1. Aplicación del Régimen del Patent Box en el contexto local................24 
3.1.1. Biotecnología

3.2. La planificación fiscal internacional y el Régimen del Patent Box.......28

3.3. Elusión Fiscal Internacional .30

3.3.1. Elusión fiscal subjetiva .31

3.3.2. Elusión fiscal objetiva .32

3.4. Instrumentos de la elusión fiscal internacional.....................................33

3.4.1. El Patent Box y los Precios de Transferencia .................................33

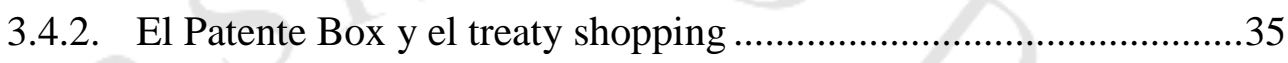

3.4.3. El Patent Box y los paraísos fiscales...........................................36

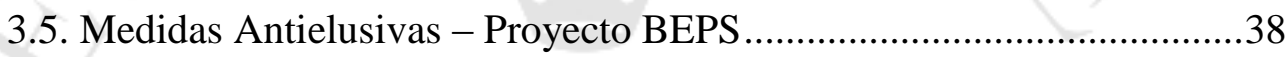

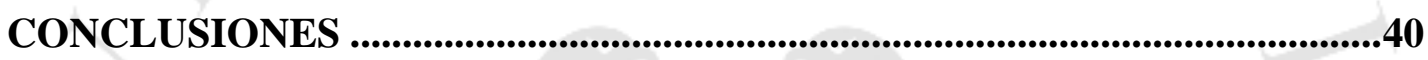

BIBLIOGRAFÍA ...............................................................................................45

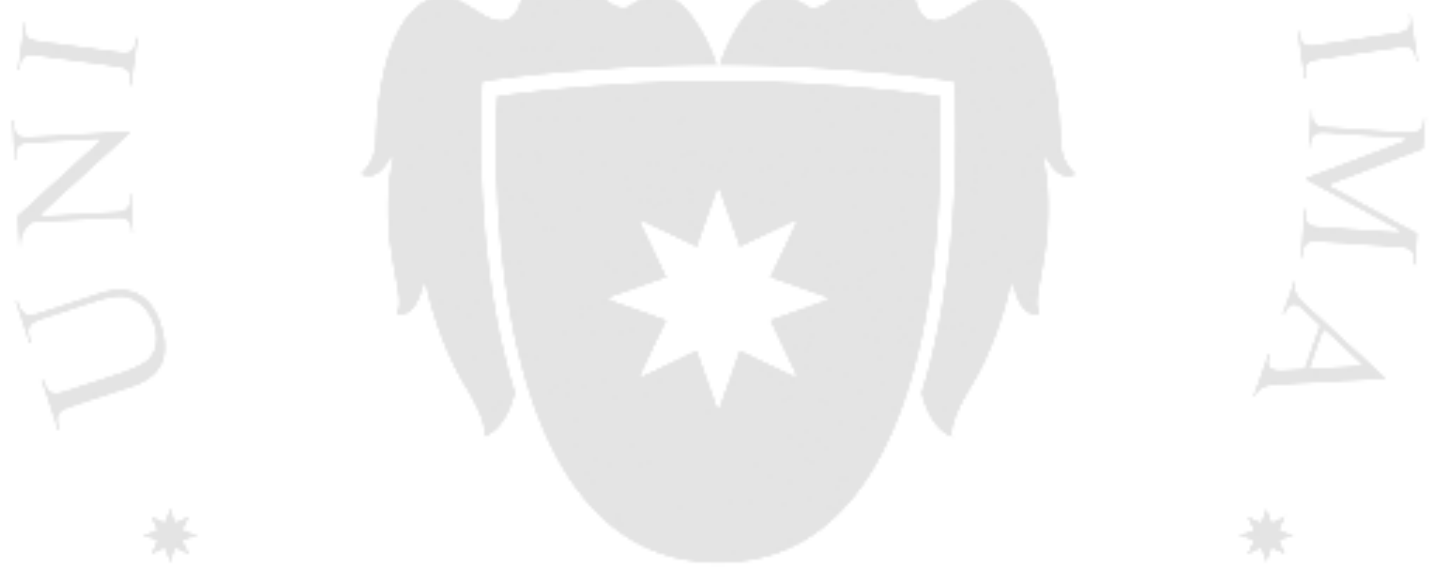




\section{INTRODUCCIÓN}

En las últimas décadas, la promoción de la investigación, desarrollo y la innovación (I + $\mathrm{D}+\mathrm{i}$ ) constituye un objetivo de vital importancia para los estados; debido a que, tales actividades impactan positivamente en las sociedades, por cuanto no solo genera la creación de nuevos puestos de trabajo, sino que mejora la competitividad de la empresa y su productividad, incrementa el valor económico de la misma, mediante la creación de nuevos activos intangibles derivados de la propiedad intelectual (patentes, marcas, software), entre otros.

No obstante, al estar frente a activos móviles fácilmente trasladables, las empresas pueden optar por ubicar tales activos en aquellas jurisdicciones que establezcan mejores opciones fiscales, es por este motivo que los estados se ven en la necesidad de no solo promover las referidas actividades, sino implementar medidas que permitan retener tales activos dentro de sus territorios, ofreciendo para ello menores tasas aplicables a los ingresos provenientes de la comercialización de patentes y otros activos móviles, esto es, el denominado régimen del "Patent Box".

Este tipo de medida implica que el sistema fiscal no sólo constituye un medio para mantener la recaudación tributaria, sino también como la vía para influir en determinados comportamientos y alcanzar diferentes objetivos. Es por ello que los Estados pueden crear medidas especiales para atraer a sus territorios ciertos negocios y actividades; así como mantenerlos dentro de sus respectivas jurisdicciones.

Ahora bien, debemos de tener en cuenta que nuestro ordenamiento jurídico no contempla el régimen del Patent Box; sin embargo, creemos que el Perú no es ajeno al contexto antes descrito; por esta razón, estudiaremos la tendencia de la regulación interna sobre este tema y la posibilidad de implementar dicho régimen dentro de nuestra legislación. 


\section{CAPÍTULO I: ACTIVIDADES DE INVESTIGACIÓN, DESARROLLO E INNOVACIÓN: IMPORTANCIAY Y REGULACIÓN}

\subsection{Importancia de las Actividades de Investigación, Desarrollo e Innovación}

En la actualidad, las actividades de investigación, desarrollo e innovación son reconocidas a nivel mundial como uno de los principales factores que influyen en el desarrollo económico de un país, debido a que los resultados positivos de tales actividades influyen en la mejora de la competitividad de las empresas, el nivel de bienestar de la población y disminuye la pobreza; en ese sentido, los beneficios provenientes de tales actividades no solo impactan en rentabilidad de las empresas, sino que también tiene un efecto positivo en los estados, esto es reconocido por Cabello y Ortiz (2013), quienes indicaron que:

Los grandes cambios tecnológicos, en especial en biotecnología y las tecnologías de la información y el conocimiento, han transformado totalmente la superestructura de la economía. El desarrollo económico y su estabilidad y sustentabilidad se sostienen ahora en la innovación tecnológica y la industria y servicios de alta tecnología. (p. 2)

Las actividades de investigación, desarrollo e innovación no solo son promovidas por los estados, sino también por instituciones internacionales, tales como la OCDE, ONU, UNESCO, entre otros, por cuanto constituyen un medio para poder alcanzar un desarrollo económico sostenible.

Asimismo, es preciso indicar que debido a la importancia de las referidas actividades, los países emergentes se encuentran en la necesidad de fomentar e implementar políticas de desarrollo en innovación y tecnología, a fin de poder disminuir la brecha existente con los países desarrollados.

Por consiguiente, el Perú no se encuentra exento a esta realidad; en consecuencia, es de vital importancia que el estado establezca políticas públicas dirigidas a contribuir en el desarrollo de un sistema nacional de ciencia, tecnología e innovación y de esta manera promover una economía competitiva; así como, avances en diversas áreas del 
conocimiento científico, cuyos resultados positivos mejoraran el bienestar de la población.

Es por esta razón, que el estado peruano mediante la Ley $\mathrm{N}^{\circ}$ 28303, Ley Marco de Ciencia, Tecnología e Innovación Tecnológica, estableció en el artículo $2^{\circ}$ lo siguiente: "El desarrollo, promoción, consolidación, transferencia y difusión de la Ciencia, Tecnología e Innovación Tecnológica (CTel), son de necesidad pública y de preferente interés nacional, como factores fundamentales para la productividad y el desarrollo nacional en sus diferentes niveles de gobierno" (párrafo 2).

De la citada norma se aprecia que el estado peruano reconoce la importancia de las actividades de investigación, desarrollo e innovación, por cuanto son consideradas como de interés nacional, hecho que se condice con lo dispuesto en el artículo $14^{\circ}$ de la Constitución Política del Perú, que indica que "Es deber del Estado promover el desarrollo científico y tecnológico del país”, máxime si tenemos en cuenta que el Perú no se caracteriza por descubrir nuevos conocimientos científicos o desarrollar nuevas tecnologías.

Es por eso que, en cumplimiento de lo previsto en la Ley $\mathrm{N}^{\circ} 28303$ antes citada, el estado implementó el denominado "Plan Nacional Estratégico de Ciencia, Tecnología e innovación para la competitividad y el desarrollo humano 2006 - 2021”, mediante el cual se establecen los lineamientos a seguir con el objetivo de fortalecer el desarrollo económico y social, el capital humano, y la interrelación entre los principales involucrados (estado y sector privado) y de esta manera lograr que el Perú sea más competitivo a nivel internacional, debiendo por ello priorizarse el área de la innovación.

El Instituto de Estadística de la UNESCO (2010) indicó que "Las actividades de innovación incluyen la generación y transferencia de conocimientos, la adquisición de tecnologías, la comercialización de productos y la investigación y el desarrollo experimental (I+D)."

Es por ello que se puede afirmar que la innovación es un factor clave para el desarrollo nacional, por cuanto este incide en la producción, esto es, en los bienes y servicios que se van a ofrecer en el mercado. Según Maximiliano García (2011), “el nivel de productividad de un país está directamente vinculado a la calidad e impulso que las políticas públicas dan al conocimiento, tanto, en su producción como en su difusión” ( $p$ 4). 
Para poder implementar políticas públicas referidas a las actividades de investigación, desarrollo e innovación es importante partir en primer lugar de las estadísticas referidas a las mencionadas actividades, y los beneficios que se obtendrían de la promoción de la inversión en tales actividades en la economía del país. El Instituto de Estadística de la UNESCO (2010) manifestó que:

Hay una relación positiva entre diversos indicadores de ciencia, tecnología e investigación y las tasas de crecimiento económico. Dentro de estos indicadores, la inversión en investigación y desarrollo (I+D) es uno de los más emblemáticos, ya que indica el esfuerzo que hacen los países para generar, en forma sistemática, nuevo conocimiento en la economía. (p. 11).

Los estados reconocen la importancia de invertir en proyectos de investigación y desarrollo; así como, de fomentar que el sector empresarial también asuma una posición activa, a fin de que asuma el desafío efectuar las mencionadas actividades. Si bien durante los últimos años, la inversión en I+D de los países de Iberoamérica creció a un ritmo superior al de los países de Europa, Estados Unidos y Canadá; sólo por debajo de Asia (RICYT, 2013) [siendo que] ese crecimiento ha sido muy marcado en términos porcentuales, con un $112 \%$ de aumento entre los años 2002 y 2011. Sin embargo, más allá de estas tasas de crecimiento, es importante tener en cuenta que se trata aún de una porción pequeña de la inversión mundial. América Latina aporta tan solo el 3,2\% de la inversión global en I+D, en tanto que Estados Unidos y Canadá contribuyen con el 33,5\%, la Unión Europea con el 25,4\% y Asia con el 35,1\%. (Organización de Estados Iberoamericanos para la Educación, la Ciencia y la Cultura, 2014)

Ahora bien en el caso de nuestro país, según el primer Censo Nacional de Investigación y Desarrollo (I + D), solo el 0,08\% del Producto Bruto Interno (PBI) gasta el Perú en investigación y desarrollo. La cifra es muy inferior por ejemplo a Colombia $(0,25 \%)$, Chile $(0,38 \%)$ y México $(0,54 \%)$ (párrafo 4$)$.

En definitiva, si un estado no es capaz de prever políticas públicas en materia de ciencia y tecnología, es bastante difícil que el sector empresarial se irrogue tal deber, en especial debido al riesgo que conlleva invertir en dichas actividades, por lo que las empresas se verán impedida de diversificar su industria, y preferirá el uso de la tecnología importada, lo que al final producirá un aumento de los costos que tendría que asumir la empresa para el desarrollo de su giro de negocio y por ende estos sobrecostos se trasladarán al precio de los productos o servicios finales, disminuyendo su competitividad 
frente a otras empresas nacionales e incluso internacionales, sin mencionar que siempre estará pendiente de los avances en el desarrollo tecnológico de otros países.

Ahora bien, teniendo en cuenta lo indicado en los párrafos anteriores, se puede concluir que dentro de los distintos mecanismos con los que cuenta un estado para promover las actividades de investigación, desarrollo e innovación $(\mathrm{I}+\mathrm{D}+\mathrm{i})$ es el de los incentivos directos, esto es, las subvenciones asumidas por parte del estado; por otro lado, tenemos a los incentivos indirectos, como por ejemplo, beneficios fiscales aplicables a los contribuyente que decidan invertir en proyectos de investigación, siendo este último mecanismo el que nos interesa.

\subsection{Régimen Tributario aplicable a las Actividades de Investigación, Desarrollo e Innovación}

Como señalamos en los párrafos anteriores, el desarrollo de nuevas tecnologías impacta de manera positiva en la economía y social del estado, es por eso que el Perú ha pasado de tener una posición indiferente a este tipo de actividades, a establecer los primeros lineamientos que regulen los aspectos necesarios para promover la investigación, el desarrollo y la innovación tecnológica.

Uno de los instrumentos utilizados por las administraciones públicas de los estados son los incentivos fiscales, sea mediante el establecimiento de un régimen especial, la posibilidad de aplicar deducciones vinculadas a las inversiones en proyectos de investigación, exenciones parciales de las rentas generadas por cesión o venta de los activos intangibles generados por tales actividades, entre otros.

Según Rosas y Mares (2016) las razones que motivan la adopción de incentivos tributarios son los siguientes:

i) se basan en incentivos de mercado, ya que las empresas deciden en qué proyectos invertir, ii) son más neutrales, ya que promueven entre todas las empresas la inversión en $\mathrm{I}+\mathrm{D}+\mathrm{i}$; iii) tienen actuación inmediata, ya que parte de los recursos destinados a I + D + i se podrán recuperar vía reducción de impuestos a corto plazo; iv) suelen tener un costo de tramitación bajo en comparación a las medidas de apoyo directo; v) no requieren un presupuesto específico, ya que el costo está expresado únicamente en termino de pérdida del ingreso financiero, vi) los costos de administración e implementación son 
relativamente bajos y vii) las medidas financieras reducen directamente el costo de I + D $+\mathrm{i}($ p. 13).

Como podemos apreciar, este tipo de medidas tributarias tienen como objetivo principal establecer un contexto favorable para promover la inversión en las actividades de I + D $+\mathrm{i}$, lo que va a tener un impacto positivo en la generación de productos, empleo e ingresos en el estado. Asimismo, es preciso señalar que estas actividades también tendrán efectos positivos en el sector privado, por cuanto a través de dichas inversiones se mejorara la capacidad de innovación de las empresas; así como, su productividad.

De ahí que intervención del estado resulte de vital importancia, debido al alto grado de incertidumbre que impera en la realización de dichas actividades, por cuanto estamos ante inversiones que en algunas ocasiones no podrán ser recuperadas o que incluso serán aprovechadas por terceros sin que estos hayan asumido ningún costo, esto es, los denominados freeriders.

Según un informe de la OCDE (como se citó en Rosas y Mares, 2016) "si no hay incentivos, el sector empresarial no tiende a invertir casi nada en innovación, quedando ésta reducida a la sustitución ocasional de maquinaria y equipos” (p. 15)

En consecuencia, es necesario una intervención estratégica del estado, caso contrario las empresas no van a privilegiar la creación de tecnologías propias, a través de la realización de inversiones en actividades de $\mathrm{I}+\mathrm{D}+\mathrm{i}$, sino que como mencionamos anteriormente, terminaran adquiriendo maquinarias desarrolladas en otros países o replicando las investigaciones efectuadas en el exterior, siendo que ambas situaciones existirá una gran dependencia por el avance tecnológico extranjero, lo que traerá como consecuencia un incremento de los costos de la empresa, reduciendo de esta manera su competitividad en el mercado, por ello corresponde analizar cómo se ha venido regulando en nuestro ordenamiento jurídico el desarrollo de las mencionadas actividades.

\subsubsection{Régimen aplicable hasta el año 2012}

Hasta el año 2012, nuestro sistema tributario no disponía ningún régimen especial aplicable a las actividades de investigación, desarrollo e innovación, por lo que los gastos en los que se incurrían se encontraban inmersos en el régimen general; en ese sentido, en primer lugar debían de cumplir con los criterios que regulan el principio de causalidad, 
previsto en el artículo $37^{\circ}$ de la Ley del Impuesto a la Renta, es decir, con el criterio de razonabilidad, proporcionalidad, entre otros.

Asimismo, los referidos desembolsos eran considerados como gastos preoperativos; en consecuencia, les resultaba aplicable lo dispuesto en el inciso g) del artículo $37^{\circ}$ antes citdado, por lo que podían deducirse en el primer ejercicio o amortizarse proporcionalmente en el plazo máximo de diez (10) años, a partir del ejercicio en que se inicie la producción o explotación (Decreto Supremo N 179-2004$\mathrm{EF}, 2004)$.

Finalmente, cabe señalar que no se establecía ninguna condición adicional más que el simple hecho que los gastos en los que se incurrieron hubiesen sido considerados como necesarios para la generación de renta o el mantenimiento de la fuente, o potencialmente necesario para la obtención de rentas, hecho que se cumple en aquellos proyectos que obtengan resultados favorables para la empresa.

\subsubsection{Régimen aplicable en el año 2013}

A través del Decreto Legislativo $\mathrm{N}^{\circ} 1124$, publicado el 23 de julio de 2012, en el diario oficial El Peruano, se produce un cambio en nuestro ordenamiento jurídico y se dispone un régimen especial para los gastos de $\mathrm{I}+\mathrm{D}+\mathrm{i}$, incorporando al artículo $37^{\circ}$ de la Ley del Impuesto a la Renta el siguiente inciso:

a.3) Los gastos en investigación científica, tecnológica e innovación tecnológica, destinada a generar una mayor renta del contribuyente, siempre que no excedan, en cada ejercicio, el diez por ciento $(10 \%)$ de los ingresos netos con un límite máximo de trescientas (300) Unidades Impositivas Tributarias en el ejercicio. La deducción a que se refiere este inciso procederá si, de manera previa al inicio de la investigación, se cumple con las siguientes condiciones (Decreto Legislativo $N^{\circ} 1124,2012$ )

En ese sentido, mediante la inclusión de este régimen especial, el legislador estableció diversas limitaciones y requisitos que debían de cumplirse a fin de que los gastos vinculados a las actividades de $\mathrm{I}+\mathrm{D}+\mathrm{i}$ sean considerados como deducibles, dado que se buscaba restringir los abusos en la utilización de este mecanismo en desmedro de la recaudación tributaria.

Una de las limitaciones que preveía este régimen especial era que los proyectos debían de estar destinados a la generación de una mayor renta; asimismo, disponía límites 
cuantitativos a los gastos, por cuanto estos anualmente no debían de superar el $10 \%$ de los ingresos netos con un límite máximo de trescientas (300) Unidades Impositivas Tributarias en el ejercicio; en ese sentido, este régimen no parecía ser muy favorable para la promoción de la inversión en $\mathrm{I}+\mathrm{d}+\mathrm{i}$, por cuanto además de las restricciones antes descritas, dicha norma condicionaba la deducción a ciertas formalidades, como por ejemplo que el proyecto debía de ser calificado como científico por la CONCYTEC, entre otros, los cuales no resultaron atractivos para el sector empresarial.

\subsubsection{Régimen aplicable en el año 2014}

En vista de ello, el legislador modificó el referido régimen, mediante la Ley $\mathrm{N}^{\circ} 30056$, "Ley que modifica diversas leyes para facilitar la inversión, impulsar el desarrollo productivo y el crecimiento empresarial", publicada en el diario oficial el 2 de julio de 2013, en el que a su vez se estableció un régimen transitorio para los gastos de I + D + i incurridos en el ejercicio 2013; así como aquellos gastos en los que se incurra en los ejercicios 2014 y 2015.

Esta ley establecía que los gastos en proyectos de investigación científica, tecnológica e innovación serían deducibles, ya sea que estos se encontraran vinculados o no al giro del negocio, siempre y cuando hubiesen sido calificados como tal por las entidades públicas o privadas, por ejemplo la CONCYTEC, caso contrario solo se deduciría un $65 \%$ de los gastos, siempre que la calificación se hubiese producido dentro de los seis meses posteriores a la fecha de presentación de la declaración jurada anual; asimismo, se eliminó el límite cuantitativo antes descrito; no obstante, estas modificaciones no significaron un verdadero incentivo, por cuanto el tratamiento era similar a los demás gastos.

En efecto, este régimen solo establecía diversas condiciones para que las empresas pudieran acceder a la deducción de los gastos efectuados en proyectos de investigación científica y tecnológica, mas no establecía un incentivo para efectuar tales proyectos, por lo que al final no causo un gran impacto, al no promover las actividades de investigación, desarrollo e innovación. 


\subsubsection{Régimen aplicable aplicable a partir del año 2016}

Por esta razón, el 13 de marzo de 2015 se publicó la Ley №30309, “Ley que promueve la investigación científica, desarrollo tecnológico e innovación tecnológica", mediante el cual se estableció un beneficio tributario para los gastos en $\mathrm{I}+\mathrm{D}+\mathrm{i}$ que se inicien a partir de 1 de enero de $2016^{1}$ y consiste en el otorgamiento de una deducción adicional (adicional a la deducción del 100\% del gasto efectuado), es decir, se dispone que los contribuyentes que realicen los mencionados gastos, vinculados o no al giro de negocio de la empresa, y que cumplan con los requisitos establecidos en la referida ley, podrán acceder al $75 \%$ como deducción adicional, en caso el proyecto sea realizado directamente por el contribuyente o mediante centros de investigación científica; o de 50\%, en caso el proyecto sea realizado mediante centros de investigación científica de desarrollo tecnológico o de innovación no domiciliados en el país.

Con esta ley se busca que un mayor número de empresas innoven y se diversifiquen, por cuanto tiene como objetivo principal que cada vez más las empresas inviertan en proyectos de I + D + i que impacten en su productividad y competitividad.

Ahora bien, a fin de otorgar la deducción adicional, se exige que los gastos desembolsados se encuentren vinculados a actividades de $I+D+i$, por lo que a fin de controlar la aplicación de este régimen es necesario tener en cuenta lo que debe de entenderse por investigación científica, desarrollo tecnológico e innovación tecnología, para ello, la Ley del Impuesto a la Renta en el inciso a.3 del artículo $37^{\circ}$ dispone las siguientes definiciones:

i. Investigación científica: Es todo aquel estudio original y planificado que tiene como finalidad obtener nuevos conocimientos científicos o tecnológicos, la que puede ser básica o aplicada.

ii. Desarrollo tecnológico: Es la aplicación de los resultados de la investigación o de cualquier otro tipo de conocimiento científico, a un plan o diseño en particular para la producción de materiales, productos, métodos, procesos o sistemas nuevos, o sustancialmente mejorados, antes del comienzo de su producción o utilización comercial. iii. Innovación tecnológica: Es la interacción entre las oportunidades del mercado y el conocimiento base de la empresa y sus capacidades, implica la creación, desarrollo, uso

\footnotetext{
${ }^{1}$ Siempre que sobre aquellos no se realicen deducciones al amparo del inciso a.3) del artículo37 de la Ley del Impuesto a la Renta.
} 
y difusión de un nuevo producto, proceso o servicio y los cambios tecnológicos significativos de los mismos. Se considerarán nuevos aquellos productos o procesos cuyas características o aplicaciones, desde el punto de vista tecnológico, difieran sustancialmente de las existentes con anterioridad. Consideran la innovación de producto y la de proceso. (Ley $\mathrm{N}^{\circ} 30309,2015$ )

Asimismo, el inciso y) del artículo $21^{\circ}$ del Reglamento del Impuesto a la Renta complementa las mencionadas definiciones al establecer que:

3. Con relación a lo establecido en los acápites i. y iii. del inciso a.3) del artículo $37^{\circ}$ de la Ley se tendrá en cuenta lo siguiente:

a. En la investigación científica:

i. Se entiende por investigación básica a la generación o ampliación de los conocimientos generales científicos y técnicos no necesariamente vinculados con productos o procesos industriales o comerciales.

ii. Se entiende por investigación aplicada a la generación o aplicación de conocimientos con vistas a utilizarlos en el desarrollo de productos o procesos nuevos o para suscitar mejoras importantes de productos o procesos existentes.

b. En la innovación tecnológica:

i. Se entiende por innovación de producto a la introducción de un bien o de un servicio nuevo, o significativamente mejorado, en cuanto a sus características funcionales o en cuanto al uso al que se destina.

Las innovaciones de producto pueden utilizar nuevos conocimientos o tecnologías, o basarse en nuevas utilizaciones o combinaciones de conocimientos o tecnologías ya existentes.

ii. Se entiende por innovación de proceso a la introducción de un nuevo, o significativamente mejorado, proceso de producción o distribución que impliquen atributos funcionales nuevos o sustancialmente diferentes. Ello implica cambios significativos en las técnicas, los materiales y/o los programas informáticos. (Decreto Supremo $N^{\circ}$ 220-2015-EF, 2015).

Por su parte, el citado reglamento prevé un listado de actividades que deben de ser excluidas de las definiciones antes detalladas, dentro de ellas tenemos por ejemplo que no constituye investigación científica, entre otros, la enseñanza y formación de personal que se imparten en universidades e instituciones especializadas de enseñanza superior, 
con excepción de la investigación efectuada por los estudiantes de doctorado en las universidades.

En ese sentido, para poder determinar si el proyecto que realizará la empresa califica como una actividad de investigación, desarrollo o innovación se deberá de analizar si se encuentra inmersa en las definiciones antes detalladas o si se encuentra en la lista de actividades excluidas por el propio régimen, caso contrario no le será aplicable el beneficio tributario.

En resumen, los requisitos que estable el régimen vigente son: i) Los proyectos de Investigación científica, desarrollo tecnológico e innovación tecnológica deben ser calificados como tales, por las entidades públicas o privadas que, atendiendo a la naturaleza del proyecto establezca el Reglamento. La calificación del proyecto debe efectuarse en 30 días; ii) El proyecto debe ser realizado directamente por el contribuyente o mediante centros de investigación científica, de desarrollo tecnológico o de innovación tecnológica. En ambos casos, deben estar autorizados para realizar los proyectos por alguna de las entidades que establezca el Reglamento. Los investigadores y especialistas deben registrarse en Directorio DINA de CONCYTEC; iii) Los contribuyentes deberán llevar cuentas de control por cada proyecto. Las que deberán estar debidamente sustentadas. De tratarse de varios proyectos de $\mathrm{I}+\mathrm{D}+\mathrm{i}$, las cuentas de control deben permitir distinguir los gastos en cada proyecto; y iv) En caso el resultado fue positivo, este podrá ser registrado en el Instituto Nacional de Defensa de la Competencia y de la Protección de la Propiedad Intelectual (INDECOPI).

Asimismo, si bien este régimen permite una deducción adicional del 75\% y 50\%, también establece un límite cuantitativo, por cuanto dispone que no podrá exceder en cada caso del límite anual de 1,335 UIT (aproximadamente S/.5.1 millones).

Ahora bien, desde la vigencia de la Ley $\mathrm{N}^{\circ} 30309$, han sido muy pocas las empresas que accedieron a los beneficios tributarios establecido en dicha norma, entre ellas, la empresa Backus, hecho que hace preguntarnos si este tipo de régimen resulta lo suficientemente atractivo para el sector privado. Al respecto, Maria Julia Saenz (Como se citó en Claudia Valdiviezo, 2016), directora de planeamiento de impuestos de Backus, indicó que "Ya en términos de impuestos, ese crédito adicional de 75\% que obtendremos es de S/.1.2 millones, tomando en cuenta el límite máximo permitido. Es un monto chiquito, porque nosotros pagamos S/.450 millones en IR” (párrafo 4). 
Como se aprecia, este incentivo tributario resulta insuficiente para las empresas que obtienen grandes márgenes de ganancias, por lo que no se encuentran incentivadas a invertir en actividades de investigación, desarrollo e innovación, siendo que por el contrario, en caso se obtengan resultados positivos en este tipo de actividades, se produciría un incremento de las rentas sujetas a gravamen, a las que se les tendrían que aplicar un tasa de $29.5 \%$.

En ese sentido, no debería de sorprendernos que sean pocas las empresas que optaron por calificar a la aplicación del beneficio previsto en la Ley $\mathrm{N}^{\circ} 30309$, máximo si otros países que ofrecen mayores beneficios tributarios a las actividades de $\mathrm{I}+\mathrm{D}+\mathrm{i}$ no solo sustentadas en la deducibilidad de los gastos incurridos en el desarrollo de proyectos de investigación, sino en la implementación de tasas menores paras los ingresos derivados de los mencionados proyectos. Uno que ha tenido una mayor aceptación en diversos estados ha sido el denominado Patent Box, el cual será analizado en el siguiente capítulo. Este incentivo se sustenta en el hecho de que a fin de promover los procesos de innovación, el estado disponga regímenes especiales para la explotación de los resutados de las actividades de $\mathrm{I}+\mathrm{D}+\mathrm{i}$. 


\section{CAPÍTULO II: MARCO CONCEPTUAL DEL PATENT BOX}

\subsection{Orígenes y concepto del Patent Box}

Los regímenes tributarios tuvieron sus orígenes dentro de una economía muy controlada y limitada, la cual se caracterizaba por un escaso desplazamiento de los bienes que generaban la renta. Era usual que la mayoría de las empresas solo operasen dentro de sus jurisdicciones, por lo que las Administraciones Tributarias no tenían problemas en determinar cuáles eran las operaciones sujetas a gravamen. No obstante, el fenómeno de la globalización ha traído como consecuencia una integración de las economías; así como, avances en las áreas de la tecnología, ciencia e información.

Estos avances generaron que actualmente el mayor valor económico de las empresas se sustente en los activos intangibles que posean o desarrollen, motivo por el cual cada vez más las empresas invierten en actividades de investigación, desarrollo e innovación $(\mathrm{I}+\mathrm{D}+\mathrm{i})$, con el fin de obtener nuevos activos y de esa manera generar ganancias mediante su explotación (cesión); sin embargo, al estar frente activos móviles que no se encuentran vinculados a un área geográfica determinada, es usual que se utilice esta flexibilidad para reducir el pago de los impuestos que le correspondería asumir por los ingresos obtenidos por la comercialización de los activos intangibles, por lo que normalmente estos son alocados en aquellas jurisdicciones que poseen menores tasas o regímenes tributarios muy favorables y de esta manera reducir su carga fiscal.

Es en este contexto que los países han ido implementando regímenes preferenciales aplicables a la propiedad intelectual o el denominado patent box, cuyo objetivo no solo se centra en fomentar la creación de nuevas tecnologías, sino también en atraer inversiones a sus respectivas jurisdicciones, o simplemente mantener tales inversiones en el territorio donde se generó el mencionado activo.

El primer país en adoptar este tipo de régimen fue Irlanda en al año 1973, mediante el "Patent Royalties exemption", que establecía que las empresas domiciliadas gozarían de una exención total del impuesto a la renta de los ingresos derivados de la explotación 
de patentes, la que por razones presupuestarias estuvo vigente hasta el año 2010; sin embargo, fue nuevamente implementado en el año 2014, pero bajo otros términos.

Posteriormente, este tipo de régimen fue adoptado lentamente por otros países, Francia y Hungría lo hicieron a principios del año 2000, seguido de Holanda y Luxemburgo en el año 2007. Desde entonces, otros países, incluyendo el Reino Unido, han adoptado este tipo de beneficio fiscal, siendo que la mayoría que incluyeron el Patent Box dentro de su sistema tributario son miembros que conforman la Unión Europea.

Esta situación se condice con las metas previstas en la Estrategia de Lisboa, también conocida como Agenda de Lisboa o Proceso de Lisboa, establecido en el año 2000, mediante un acuerdo de los jefes de estado de los países miembros de la Unión Europea, estableciéndose el siguiente objetivo: "Hacer de Europa en 2010 la economía más próspera, dinámica y competitiva del mundo capaz de crecer económicamente de manera sostenible con más y mejores empleos y con mayor cohesión social” (p. 20)

Es por esta razón que en marzo de 2002, en el Consejo Europeo de Barcelona, se acordó que a fin de cumplir con el objetivo previsto, se debía de poner mayor énfasis en mejorar las actividades vinculadas a la investigación y desarrollo; así como en la innovación, lo que conllevaría a su vez a la implementación de nuevos beneficios fiscales vinculadas a tales actividades.

Asimismo, se constituyó el "Programa Marco de la Unión Europea", el cual tenía como objetivo principal la mejora de la competitividad mediante el financiamiento de actividades de investigación, innovación y desarrollo tecnológico realizadas tanto por las empresas como las instituciones de investigación de los países miembros o estados asociados.

Por su parte, es preciso tener en cuenta que la Estrategia de Lisboa expiró en el año 2010, siendo reemplazada por un nuevo proyecto denominado "Europa 2020", que de manera similar tiene como objetivo desarrollar una estrategia integrada de crecimiento y empleo, que estará vigente hasta el año 2020, siendo que las nuevas políticas económicas y fiscales que vayan a ser adoptadas por los países miembros de la Unión Europea deberán considerar los cambios producidos por el fenómeno de la globalización, el desarrollo de nuevas tecnologías, los lineamientos previstos por la OCDE, entre otros. 
Es por ello que durante la última década, el "Patent Box" o también conocido como "Intellectual Property Box" ha sido incluido como parte de la política fiscal en diversos países alrededor del mundo.

Ahora bien, como mencionamos, el Patent Box es un incentivo fiscal, que prevé la exención del impuesto a la renta sobre los ingresos generados por determinados tipos de propiedad intelectual, de preferencia patentes.

Para Isabel Fano (como se citó en Bustillos Arancha, 2014), el Patent Box puede ser definido como "un incentivo fiscal que consiste en la aplicación de una reducción del Impuesto de Sociedades sobre las rentas procedentes de determinados intangibles desarrollados por la empresa". (párrafo 8)

El Patent Box es un régimen preferencial que difiere de otros incentivos fiscales, como por ejemplo las deducciones aplicables a las actividades de investigación, desarrollo e innovación $(\mathrm{I}+\mathrm{D}+\mathrm{i})$, que permiten deducir los gastos en los que se incurrió para el desarrollo de las referidas actividades o un porcentaje de dichos gastos aplicable contra la base imponible, siempre y cuando, se cumpla con las condiciones previstas en el ordenamiento jurídico que lo contemple; en consecuencia, este tipo de deducciones constituyen un incentivo fiscal a la actividad, toda vez que se encuentra vinculada a cubrir el gasto en el que se incurrió para el desarrollo o creación del activo durante las primeras fases de la actividad, por lo que constituye un incentivo que de manera indirecta pretende fomentar la inversión en este tipo de actividades, y de esa manera evitar las subvenciones por parte del estado.

Es por ello que el Patent Box es un incentivo al resultado, es decir, a las fases siguientes a la creación del activo, por cuanto se encuentra referido a la aplicación de una menor tasa a los ingresos obtenidos de la comercialización de los activos intangibles o derechos de propiedad intelectual, por lo que estamos ante un incentivo directo que tiene por objeto promover las inversiones por parte de las empresas en las actividades de investigación, desarrollo e innovación $(\mathrm{I}+\mathrm{d}+\mathrm{i})$, mediante la reducción de los impuestos a pagar por la explotación de los activos intangibles que se hubiesen generado en los proyectos de investigación emprendidos por la empresa.

En definitiva, el régimen del Patent Box es el mecanismo principal instaurado por la mayoría de países a fin de no solo promover las inversiones en las actividades antes señaladas, sino que también tiene como objetivo subyacente el atraer capitales a sus 
territorios, es decir, que el derecho de patentes u otros intangibles sean alocados en sus territorios, debido a que estos activos benefician a la sociedad en su conjunto.

\subsection{Principales Implicancias del Régimen del Patent Box}

Como indicamos en los párrafos anteriores, el denominado Patent Box es un incentivo a las actividades de $\mathrm{I}+\mathrm{D}+\mathrm{i}$, al suponer una reducción del gravamen para aquellas empresas que desarrollen nuevos productos o procesos protegidos por los derechos de propiedad intelectual, por ejemplo el derecho de patentes.

En ese sentido, Elizabeth Gil García (2016) indicó que “el objetivo de los IP boxes es conceder un incentivo adicional a las empresas para conservar y comercializar las patentes existentes y desarrollar nuevos e innovadores productos patentables" (párrafo 2), lo que generaría a su vez que aquellos países que decidan implementarlo resulten más atractivos para las empresas dedicadas a ese tipo de actividades; sin embargo, este tipo de régimen dependiendo del uso que se le dé podría generar una disminución de la recaudación del estado, por lo que a continuación analizaremos las principales implicaciones del Patent Box.

\subsubsection{Ventajas del Régimen del Patent Box}

Una de las principales ventajas del Patent Box es la atracción y generación de activos intangibles de propiedad intelectual en el estado en el que se implemente dicho mecanismo, Ignacio Gómez Acebo (como se citó en Bustillos Arancha, 2014), menciona que "esta medida fiscal que incentiva la innovación no sólo es un interesante impulso para los nuevos proyectos de los emprendedores, sino que también es una manera de fomentar la internacionalización en las empresas.” (párrafo 2)

En ese sentido, las empresas que obtengan resultados positivos de los proyectos de investigación, desarrollo e innovación podrán comercializar los activos propiedad intelectual no solo dentro de la jurisdicción en la que se encuentren, sino a otros países, rentabilizando al máximo el citado activo; dado que como señala Elzaburu (como se citó en Bustillos Arancha, 2014) el Patent Box "pone en valor los resultados de I+D+i al cederlos a terceros; es independiente de la base imponible de la compañía; y se aplica a 
la cesión de uso o explotación, por lo que no se pierde la propiedad sobre el activo" (párrafo 5)

Debido a esto, las empresas que posean tales activos podrán obtener ingresos de la cesión de los derechos de los activos intangibles vinculados a la propiedad intelectual, mediante las regalías o cánones que les corresponda pagar a los cesionarios.

Asimismo, según Alba María López y Cristina Espín (como se citó en Bustillos Arancha, 2014) consideran que otra de las ventajas que se derivan de la aplicación de esta medida es que esta "es compatible con otras deducciones fiscales (también al I+D+i), préstamos y subvenciones." (párrafo 5).

Recordemos que el Patent Box es un incentivo directo de las actividades de innovación aplicable a la fase de resultados, es decir, se encuentra referido a la etapa de comercialización del activo de propiedad intelectual, por lo que no se sobrepondría a la aplicación de otros incentivos fiscales tales como deducciones, amortizaciones o depreciaciones de los activos intangibles que hayan sido establecidos en el ordenamiento jurídico, siendo que por el contrario podrían aplicarse de manera conjunta.

El Patent Box también permitiría la transferencia y la rentabilización del conocimiento entre las empresas que formen parte del mismo grupo, mejorando el valor económico de cada una de estas, y a su vez reduciendo los costos en los que se pudiera incurrir, en caso cada una de ellas hubiese decidido desarrollar el mismo activo intangible, por lo que se incrementaría la eficiencia del grupo económico.

Por otro lado, este tipo de actividades requiere de personal capacitado; en consecuencia, habría una mayor demanda de profesionales dedicados a los rubros de investigación altamente calificados, por lo que de manera indirecta reduciría el desempleo, e incrementaría la recaudación por las rentas de trabajo que se obtendrían de tales trabajadores; además, que implicaría que el estado se preocupe por mejorar la calidad de la educación, por cuanto constituye la base de la formación del personal requerido para desarrollar este tipo de actividades.

Asimismo, dado que el Patent box tiene como objetivo promover que las empresas realicen actividades de innovación, el país en el cual se establezca dicho régimen podrá adaptarse al nuevo económico, por cuanto estará a la vanguardia de las nuevas tecnologías en la industria, agricultura, salud, medio ambiente, energía, educación y otros 
sectores, reduciendo de esta manera la llamada brecha tecnológica que los pudiera separar del mundo industrializado, conforme retomaremos más adelante.

\subsubsection{Desventajas del Régimen del Patent Box}

Dentro de las principales desventajas que existen en la aplicación del Patent Box se encuentra la posible erosión a la base imponible en la que podrían incluir las empresas que desarrollen las actividades de innovación, por cuanto estas son vistas como una actividad internacional, por lo que probablemente se opte por desarrollar la fase inicial del proceso de $\mathrm{I}+\mathrm{D}+\mathrm{i}$ en un territorio distinto de aquel en el que se vaya a solicitar la protección de los derechos de propiedad intelectual del activo intangible obtenido, siendo que incluso se empleará un tercer país para efectuar la comercialización del mencionado activo. Esa planificación fiscal empresarial conlleva tanto la pérdida de ingresos públicos como la posibilidad de distorsionar la competencia.

En efecto, el régimen del patent box puede resultar potencialmente dañino al suponer una nula o baja tributación efectiva. Igualmente y en esta misma línea, este incentivo acentúa el riesgo de deslocalización de intangibles y del llamado " profitshifting", esto es, la transferencia artificial de beneficios.

Casos como el de Google, Amazon y Facebook evidencian las consecuencias derivadas de las nuevas medidas fiscales adoptadas por estos sistemas impositivos vinculados a la propiedad intelectual y demás activos intangibles, lo que se ve agudizado por el hecho que la legislación interna resulta insuficiente para poder ejercer algún criterio de conexión sobre las rentas obtenidas en las jurisdicciones que ofrecen estas tasas reducidas.

Este tipo de planificaciones fiscales ha provocado que tanto los países emergentes como los países desarrollados se vean afectados en su recaudación, pues las empresas buscan estas plataformas para evitar o retrasar el pago de determinados impuestos, utilizando para ello mecanismos y estrategias legales.

Estos efectos negativos derivados de la aplicación del Patent Box son los que intenta disminuir el Action Plan on Base Erosion and Profit Shifting (BEPS) de la OCDE.

Según Pasquale Pistone (2014): 
El proyecto BEPS debería "desbaratar" aquellas áreas de la planificación fiscal internacional en la que las grandes empresas o grupos multinacionales se benefician de condiciones fiscales privilegiadas bajo la justificación de promover estructuras de I+D, no existiendo en un gran número de casos una conexión real directa entre la I+D y la renta generada por la actividad (párrafo 6).

La OCDE pone su atención en los regímenes tributarios preferenciales, especialmente, en los regímenes de propiedad industrial e intelectual, siendo que empieza por definir las características que debería poseer el aludido régimen.

Para que un régimen sea considerado preferencial, debe en primer lugar referirse a rentas procedentes de actividades que por su naturaleza son fácilmente desplazables (activos móviles), por ejemplo dividendos, regalías u otras rentas derivadas de la explotación de los activos intangibles. En segundo lugar, debe conceder cualquier forma de beneficio fiscal, tales como una deducción, una reducción en la base, un crédito o un tipo de gravamen reducido- en comparación con los principios tributarios generales del país en cuestión (Gil García, 2016, párrafo 13).

Ciertamente, según los principios de capacidad contributiva e igualdad existe una prohibición general de ofrecer privilegios fiscales o un tratamiento preferente. No obstante ello, los incentivos fiscales, como el Patent Box, son compatibles con esos principios siempre y cuando su introducción esté legitimada por valores constitucionales u otras prioridades de interés general.

Es por ello, que la OCDE señala la necesidad de una actividad sustantiva (nexus approach) como requisito para la aplicación de los regímenes preferenciales aplicables a aquellas empresas que efectivamente hayan desarrollado el proyecto de investigación que generó el activo de propiedad intelectual.

En consecuencia, el Plan de Acción sobre BEPS establece directrices que buscan combatir los perjuicios que se generan de la aplicación ilegítima de los regímenes preferenciales, teniendo en cuenta para ello factores como la transparencia y la sustantividad (Acción 5).

Como desarrollaremos en el siguiente capítulo, la OCDE propuso el enfoque del nexo (nexus approach) como forma de vincular los gastos en $\mathrm{I}+\mathrm{D}+\mathrm{i}$ con la concesión de beneficios fiscales. Dicho de otra forma, se alinea la tributación de los beneficios 
derivados de la propiedad industrial e intelectual con el lugar en el que la actividad creadora de esos intangibles ha sido desarrollada (Gil García, 2016, párrafo 13).

Ahora bien, a fin de entender cómo funciona el régimen del Patent Box, corresponde analizar de manera general algunas legislaciones que prevén el citado incentivo.

\subsection{Legislación Comparada}

\subsubsection{Bélgica}

En el año 2007, Bélgica implementó un régimen del Patent Box denominado "Patent income deduction" regulado en los artículos 205/1 a 205/4 del Código del Impuesto a la Renta, que permitía que las empresas domiciliadas o los establecimiento permanentes de empresas no domiciliadas dedujeran el $80 \%$ de los ingresos obtenidos de ciertas patentes; en consecuencia, solo al $20 \%$ de tales ingresos se les aplicaba la tasa del impuesto a las sociedades $(34 \%)$.

Sin embargo, dicho régimen fue reemplazado en el año 2016, mediante el régimen denominado "Innovation Income Deduction", a fin de cumplir con los requerimientos previstos en la acción 5 del plan BEPS. Este nuevo régimen incrementó el porcentaje de deducción a $85 \%$; además que no se limita a los ingresos obtenidos de patentes, sino que incluye a los medicamentos huérfanos ${ }^{2}$, fitomejoradores y el software. Por su parte, este régimen excluye a las marcas.

Esta deducción es aplicable a aquellos que hayan desarrollado los activos de propiedad intelectual; así como, a los que hayan adquirido los derechos de tales activos o la licencia para explotarlo de terceras empresas no vinculadas (Centros de Investigación).

Finalmente, este régimen se aplica sobre los ingresos netos, es decir, después de la deducción de los gastos corrientes del año en los que se incurrió para el desarrollo del activo de propiedad intelectual, incluidos los gastos de adquisición de dicho activo, los

\footnotetext{
${ }^{2}$ Se denomina así al medicamento destinado a diagnosticar, prevenir o tratar una enfermedad que afecte a un grupo reducido de personas, por lo que su comercialización resulte poco probable, y en consecuencia no son ampliamente desarrollados por la industria farmacéutica.
} 
gastos relacionados con la investigación y el desarrollo en lo que tuvo q incurrir o en los que incurrió la empresa subcontratada para la generación del referido activo.

\subsubsection{Luxemburgo}

El régimen de Patent Box fue introducido en diciembre del año 2007 en el artículo 50bis de la Ley del Impuesto a la Renta, estableciendo que las empresas domiciliadas; así como, los establecimientos permanentes de empresas no domiciliadas podían deducir el $80 \%$ de los ingresos netos obtenidos de la explotación o de la licencia a explotar determinados activos de propiedad intelectual, tales como patentes, marcas, diseños, modelos, software desarrollados o adquiridos a partir del 31 de diciembre de 2007.

Para poder aplicar este régimen, la empresa debe de ser el propietario económico de los derechos de propiedad intelectual del activo intangible, es decir, tales derechos deben de otorgarle la explotación exclusiva del activo dentro del territorio. Si bien no dispone condiciones específicas para el desarrollo del activo intangible, por lo que este puede ser efectuado por la propia empresa o adquirido directamente de otra compañía, esta no puede ser adquirida de una empresa vinculada de manera directa.

Por otro lado, a fin de calcular el ingreso neto sobre el cual se va a aplicar la deducción prevista por este régimen se debe de deducir los gastos de investigación y desarrollo en los que se incurrieron, los intereses, la amortización y otros gastos.

Finalmente, cabe mencionar que el 1 de julio de 2016, la Ley de Presupuesto derogó el Régimen de Patent Box; debido a que no seguía los lineamientos de la acción 5 del plan BEPS; sin embargo, este proceso de derogación se efectuará de manera progresiva, por cuanto se estableció un régimen transitorio de 5 años, por ello se dispuso que el régimen del Patent Box seguirá vigente para aquellas compañías que venían aplicándolo hasta el 30 de junio de 2021, y que existirán reglas especiales para los nuevos beneficiarios.

\subsubsection{Holanda}

Holanda implementó el régimen denominado "Innovation Box" en el año 2007, el cual en un inició estableció una tasa de 10\%, aplicable únicamente a los ingresos obtenidos de la explotación de patentes, posteriormente este régimen fue modificado, procediendo a 
incluir a los demás activos de propiedad intelectual que provengan de las actividades de investigación y desarrollo calificados como tal mediante el gobierno Holandés, por lo que de esta manera se excluía a las marcas, logos, nombres comerciales, entre otros que no provengan de dicha actividad, asimismo, redujo la tasa a 5\%.

Este tipo de régimen es aplicable a las empresas domiciliadas en Holanda; así como, a los establecimientos permanentes de empresas no domiciliadas, siempre y cuando, estos establecimientos efectúen el pago de impuesto en el citado país; además que, tales entidades deben de ser el propietario económico de los activos intangibles y por ende asumir los riesgos derivados de tal condición.

A su vez, se debe de tener en cuenta que este régimen establece ciertas condiciones, tales como: i) El activo de propiedad intelectual tiene que ser desarrollado por la propia entidad y bajo su propio riesgo, por lo que las actividades de investigación y desarrollo podrían efectuarse fuera del territorio holandés, a menos que hayan obtenido una declaración por parte del gobierno, en cuyo caso tales actividades deben de ser realizadas al menos un 50\% en el citado país, y solamente es aplicable para aquellos que se conviertan en activos de la empresa con posterioridad al 31 de diciembre de 2006 y ii) En el caso estemos ante derechos de patentes, se prevé que más del 30\% de los ingresos deben de ser atribuibles a los referidos derechos.

Por su parte, es preciso indicar que este régimen se aplica a los ingresos netos obtenidos, es decir, se deduce los gastos y depreciaciones vinculadas a los activos de propiedad intelectual generados de las actividades de investigación y desarrollo, siendo que se puede optar por aplicar este régimen de manera separada por cada activo. (se incluye embebed royalties)

\subsubsection{España}

El régimen del Patent Box fue introducido a inicios del año 2008, y consiste en una reducción del $40 \%$ de los ingresos obtenidos de la cesión de patentes y otros activos de propiedad intelectual.

A partir del 1 de julio de 2016 se efectúan modificaciones a la normativa española, a fin de alinearse a los acuerdos adoptados en la Unión Europea y en el Plan BEPS (Plan de acción contra la erosión de la base imponible y el traslado de beneficios) de la OCDE, (...) para frenar la elusión fiscal. La modificación más 
relevante se refiere a la fórmula de cálculo del incentivo fiscal, que establece un prorrateo de los gastos en los que ha incurrido la entidad en la generación del activo con los gastos totales derivados del mismo (...) Se establece además un régimen transitorio para las cesiones de patentes realizadas con anterioridad al 1 de julio de 2016 (Fdez Diana, 2015, párrafos 6 a 8).

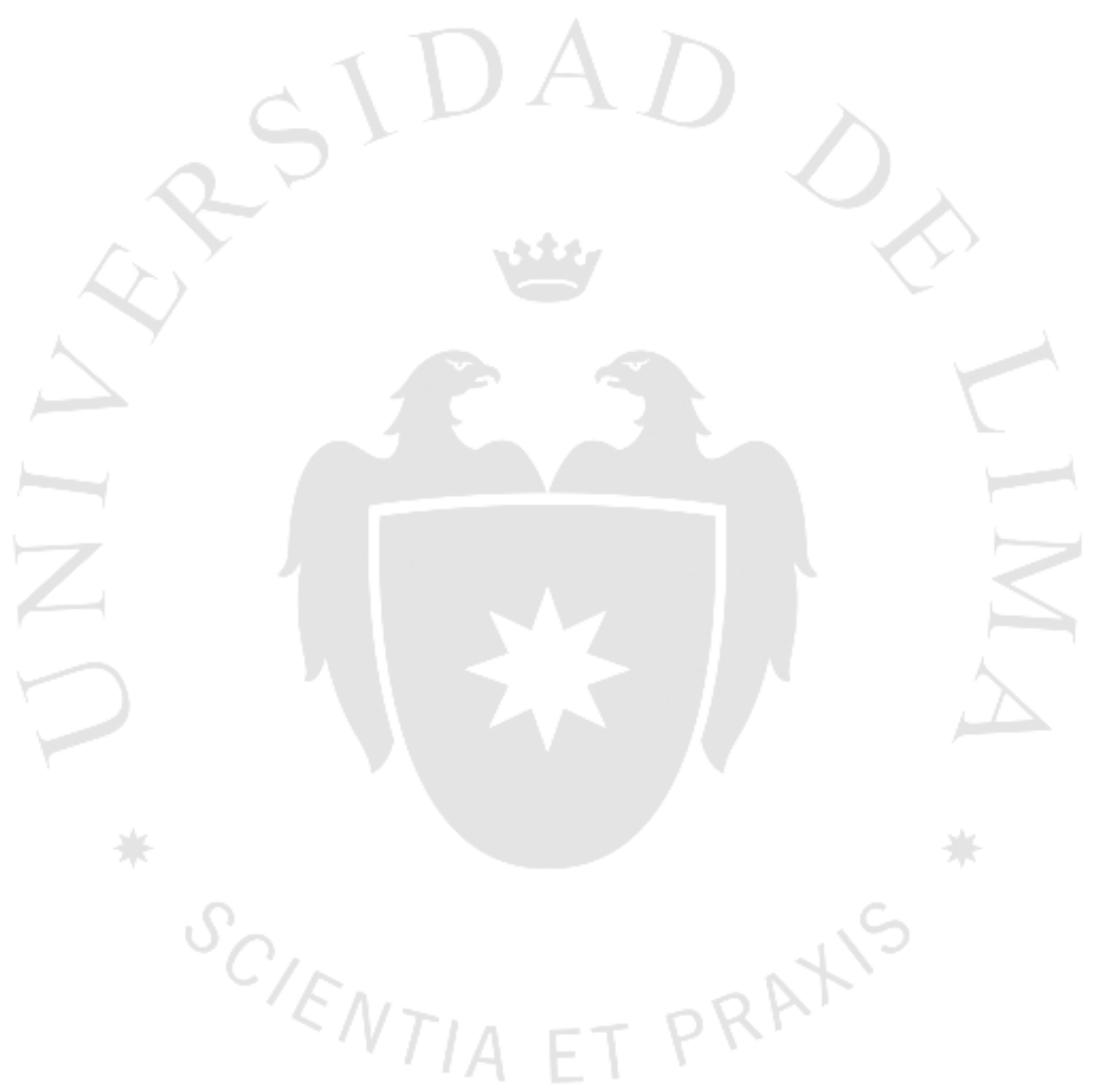




\section{CAPÍTULO III: APLICACIÓN DEL RÉGIMEN DEL PATENT BOX EN EL PERÚ Y SUS POSIBLES IMPLICANCIAS}

\subsection{Aplicación del Régimen del Patent Box en el contexto local}

En los capítulos anteriores hicimos referencias a los mecanismos implementados por el estado peruano a fin de promover la actividades de I + D + i; sin embargo, a pesar de los cambios en la legislación, estos no habrían tenido el efecto esperado, ya que no resultaban ser lo suficientemente atractivos para las empresas, debido a que solo cinco de ellas se habían acogido a la regulación prevista en la Ley № 30309.

En ese sentido, teniendo en cuenta que el desarrollo económico se sustenta en las referidas actividades, es necesario analizar si los regímenes preferenciales, como el Patent Box, constituyen una oportunidad para lograr que más empresas inviertan en proyectos de investigación e innovación, por ello en el presente capítulo se analizaran las áreas que se beneficiarían de la implementación de este régimen en el estado peruano.

En primer lugar, es preciso indicar que la situación del Perú, en lo que a avances tecnológicos se refiere, no es muy favorable, por lo que para poder mejorar nuestra posición a nivel internacional; así como, obtener un mayor crecimiento económico, debemos de evitar de replicar el desarrollo de las investigaciones e innovaciones efectuadas por los demás países, debido a que tenemos distintas situaciones socioeconómicas; además que, no poseemos las mismas capacidades de infraestructura, capital humano, recursos económicos, entre otros; en ese sentido, es primordial analizar los recursos con los que contamos a fin de poder diseñar un régimen del Patent Box acorde con nuestra realidad.

Una de las mayores ventajas con las que cuenta el Perú es la diversidad de recursos naturales, las cuales pueden constituir una plataforma para el desarrollo de proyectos de investigación e innovación, por ello es esencial dejar atrás el prejuicio de que la explotación de los mencionados recursos naturales solo generan riesgos ambientales. Esta situación es reconocida por Anabel Marín (2017), quien manifestó lo siguiente: 
Existirían nuevas oportunidades para el crecimiento económico vinculadas al aprovechamiento de recursos naturales, en entornos de políticas orientados a controlar los impactos negativos y a incentivar la diversificación productiva incorporando un mayor número de actividades, con énfasis en las que son intensivas de conocimiento, ya que tienen más opciones para la innovación continua y aumentan la tasa de retorno. (Párrafo 3).

Esta descripción es acorde con el contexto internacional, por cuanto actualmente se han dejado atrás aquellas estrategias que solo estaban orientadas al desarrollo de la manufactura sustentada en la mano de obra barata, para dar paso a otras actividades que generan mayor valor económico a la empresa, como el desarrollo de activos de propiedad intelectual, motivo por el cual algunos sistemas fiscales prevén regímenes preferenciales como el Patent box, aplicable a los ingresos obtenidos de la explotación de los referidos activos, conforme a lo señalado en el capítulo anterior.

En ese sentido, si bien no somos un país desarrollado que cuenta con empresas que se dedican a investigar nuevos avances en las ciencias de la comunicación, como Apple o Microsoft, tenemos recursos naturales que pueden ser objeto de investigación por parte de las empresas, a fin de obtener nuevos productos o innovaciones en el área del conocimiento, a los cuales se les aplicaría la protección de los derechos de propiedad intelectual, por ejemplo el derecho de patentes, y por ende al generarse un activo intangible, las empresas podrán obtener ingresos de la explotación de dichos activos; además que estos avances mejorarían la calidad de vida de las personas.

Nuestra gran diversidad en flora y fauna puede ser aprovechada por las empresas nacionales, las cuales pueden crear nuevos espacios de crecimiento económico, vinculados a los avances en la biotecnología, un ejemplo de ello son las investigaciones enfocadas en nuevos conocimientos obtenidos de los recursos naturales empleados en la creación de productos farmacéuticos o en aquellas áreas vinculadas a las agricultura, a fin de obtener semillas fortificadas, o incluso mejorar los procesos llevados en áreas como la minería, mediante la biolixiviación, es decir, este tipo de investigaciones generan oportunidades que permitirían obtener soluciones innovadoras a grandes problemas sociales como salud, escasez de alimento, entre otros, los cuales son fácilmente insertables en las cadenas globales de valor a nivel internacional.

Ahora bien, estas investigaciones vinculadas a los recursos naturales incentivaran la diversificación de la productividad de la industria nacional, por ello es necesario 
adoptar decisiones estratégicas que fomenten que las empresas nacionales inviertan en nuevos proyectos de investigación, esto incluso es reconocido por la Organización de los Estados Americanos al afirmar que:

Los países de Iberoamérica deben aplicar políticas que conduzcan a impulsar la innovación, crear e incorporar conocimiento científico y tecnológico de calidad y socialmente relevante, difundirlo y aplicarlo en las empresas y otras instituciones. En este proceso deben colaborar, tanto los investigadores, los tecnólogos y los gestores, como los empresarios, los gobiernos, las instituciones educativas, la opinión pública y otros actores de la sociedad. Todos ellos han de estar involucrados en un proceso de aprendizaje que requiere cambios profundos de mentalidad y de conductas. (p. 31)

Como podemos advertir, el estado peruano puede enfocar sus esfuerzos mediante la implementación del régimen del patent box en fomentar las actividades de investigación, desarrollo e innovación vinculadas al área de la biotecnología.

\subsubsection{Biotecnología}

Según el artículo 2 de la Convención para la Diversidad Biológica de las Naciones Unidas, se debe de entender por biotecnología como "toda aplicación tecnológica que utilice sistemas biológicos y organismos vivos o sus derivados para la creación o modificación de productos o procesos para usos específicos". (p. 6)

En consecuencia, estamos ante procesos que utilizan organismos vivos para la elaboración de productos, un ejemplo clásico de este tipo de procedimiento es la fermentación de alimentos, que mediante la proliferación de microorganismos se genera la cerveza, el yogurt, entre otros.

Por su parte, la biotecnología actualmente se caracteriza por el estudio del ADN y su estructura, es decir, de la ingeniería genética, que tiene como objetivo obtener nuevos bienes o procesos, mediante el desarrollo de actividades de investigación.

El fomento de este tipo de proyectos traería beneficios en diversas áreas como la agricultura, salud, minería, entre otros. 


\subsubsection{Agricultura}

Mediante la creación de semillas fortificadas, se puede producir alimentos de mayor calidad y resistentes a las variaciones del clima; así como, a otras plagas, también a conservar recursos como la tierra cultivable, la cual es de vital importancia para la agricultura; en consecuencia, la biotecnología es una herramienta útil para la creación de nuevos productos, y el mejoramiento de la fertilidad de la tierra; debido a que, en los últimos años se ha incrementado el problema de la desertificación de las tierras, causada por la constante producción de alimentos. Norman Borlaug (s.f), padre de la Revolución Verde y premio de la paz indicó que:

Durante la década pasada, hemos presenciado el éxito de la biotecnología vegetal. Esta tecnología ayuda a los granjeros de todo el mundo a lograr una mayor producción, al mismo tiempo que se reduce el uso de pesticidas y la erosión del suelo. Los beneficios y la seguridad de la biotecnología se han corroborado durante la última década en países en los que habita más de la mitad de la población del mundo. Lo que necesitamos es valor por parte de los líderes de estos países donde a los granjeros no les queda otra opción más que usar métodos obsoletos y menos eficientes. La revolución verde y, ahora, la biotecnología vegetal ayudan a satisfacer la creciente demanda de la producción de alimentos, al mismo tiempo que se preserva nuestro ambiente para las generaciones futuras. (párrafo 4).

Como podemos advertir, es necesario que el estado promueva el desarrollo de investigaciones que potencie nuestra agricultura, en especial si el Perú cuenta con innumerables clases de semillas, climas, y distintos tipos de pisos ecológicos, por lo que nuestra riqueza hace viable que podamos obtener resultados positivos de las mencionadas investigaciones, las cuales podrán ser registradas ante Indecopi y de esa manera obtener el derecho de patente, para después explotar el activo de propiedad intelectual.

Asimismo, este tipo de avances tendría un impacto en los ingresos de los agricultores; así como, de aquellas empresas cuyo objeto de negocio se sustente en el cultivo de alimentos; en consecuencia, el régimen del Patent Box constituye una herramienta necesaria que brinda la oportunidad de incentivar la innovación científica en el campo de la agricultura. 


\subsubsection{Minería}

El Perú se caracteriza por ser un territorio con diversos yacimientos mineros; sin embargo, no todas las actividades extractivas son realizadas de manera legal, sino que están se efectúan de manera artesanal, empleando para ello grandes cantidades de mercurio en el proceso de amalgamación del oro, los que posteriormente son desechados al río y suelos, perjudicando de esta manera la salud de los pobladores aledaños a la zona de extracción. Es por esta razón que recientes investigaciones señalan que un tratamiento alternativo para mejorar los ambientes contaminados es la Bioremediación.

Jaime Flores, Martha Ly, Nelson Tapia y Holger Maldonado (s.f) definieron a la Bioremediación "como los procesos de eliminación de metales tóxicos desde los efluentes mineros, utilizando para lograr este objetivo materiales de origen biológico" (párrafo 9)

En consecuencia, la implementación del Patent Box dentro de nuestra legislación tributaria constituye un mecanismo que traería beneficios económicos y sociales para el estado peruano, por cuanto promovería las investigaciones vinculadas a nuestros recursos naturales, máxime si la deducción de los gastos incurridos en las actividades de $\mathrm{I}+\mathrm{D}+\mathrm{i}$ dispuesta en la Ley $N^{\circ} 30309$, no ha podido cumplir con el objetivo de incrementar las inversiones en el país mediante el fomento de las referidas actividades. Sin embargo, cabe mencionar que este régimen podría traer algunas consecuencias negativas derivadas de la planificación fiscal a la que recurrirían las empresas que opten por gozar de este beneficio.

\subsection{La planificación fiscal internacional y el Régimen del Patent Box}

Como hemos señalado a lo largo del presente trabajo, la globalización ha traído como consecuencia un creciente desarrollo económico de los estados, por lo que en la necesidad de atraer inversiones adoptaron ciertas medidas, tales como la eliminación de barreras que dificultaban el libre intercambio de bienes, servicios o capitales, lo que facilitó el crecimiento de las empresas multinacionales y con ello el movimiento de capitales; en consecuencia, estas empezaron a organizar su estructura productiva en distintos estados, por lo que las rentas obtenidas se encontraban sujetas a imposición en diversas jurisdicciones. 
Por esta razón, las grandes empresas multinacionales recurren a la planificación fiscal como un medio para reducir su carga fiscal, mediante estrategias legales sustentadas en la normatividad del país donde se encuentra la empresa operativa; así como, la normativa internacional, según Pietro Adonnino (2003) este tipo de planificación debe de entenderse como:

El complejo de iniciativas de organización realizadas por las empresas sobre el plano operativo, con el objetivo de optimizar para las mismas empresas, el costo fiscal que deben de afrontar, considerando para ellos las características de los ordenamientos tributarios particulares en los que operan, sus interrelaciones, las posibilidades en que la optimización del costo fiscal pueda abstenerse de la utilización lícita de las diferencias e interconexiones existente entre los ordenamientos (p. 51).

Estamos entonces ante un concepto que se encuentra vinculado al denominado "economía de opción" que tiene como objetivo principal buscar el ahorro fiscal, para Rocío Liu Arévalo (2012), este debe de ser entendido como el "derecho que tiene todo contribuyente, todo administrado o todo sujeto de poder ordenar sus negocios en la forma que le resulte más ventajoso fiscalmente, siempre dentro de la licitud del ordenamiento" (p. 407). Dicha definición también es compartida por Guillermo Lalanne (2005), al señalar que:

El ahorro fiscal al que se llega a través de la economía de opción, no se hace desconociendo norma alguna, ni realizando maniobras de elusión, tampoco mediante abuso de derecho, sino que lo hace aplicando correctamente la norma o valiéndose de los resquicios que el propio legislador, por desconocimiento o voluntad, ha establecido al momento de regular determinada situación o negocio (p 111 y 112).

En ese sentido, la economía de opción es un planeamiento fiscal legal, mediante el cual las empresas obtienen un ahorro a través de la utilización de estructuras que se encuentra dentro de lo que la legislación permite; en consecuencia, la economía de opción no es sancionable, toda vez que constituye una alternativa dirigida a obtener un ahorro fiscal lícito.

Sin embargo, existen ciertas prácticas de planificación fiscal que tienen como objetivo eludir el pago de tributos, ya que como bien sabemos, el impuesto a la renta se aplica sobre los beneficios empresariales obtenidos en el ejercicio fiscal, por lo que mediante esquemas complejos tratan de trasladar los beneficios obtenidos hacia países de nula o baja imposición, simular operaciones que darían origen al nacimiento de la 
obligación tributaria o hacen un uso excesivo de empresas "cascaron" para de esa manera ocultar al beneficiario efectivo de las rentas empresariales, es decir, estamos ante casos de elusión fiscal internacional.

\subsection{Elusión Fiscal Internacional}

César García Novoa (2005) indica que la elusión tributaria consiste en "buscar a través de instrumentos lícitos, fórmulas negociales menos onerosas desde el punto de vista fiscal, a través de alternativas negociales que provocan una evitación o reducción del tributo" (p 121).

Por su parte, Fernando Zuzunaga del Pino (2012), indicó que se debe de entender por elusión tributara como al "evitamiento de un hecho imponible a través de una figura anómala que no vulnera en forma directa la regla jurídica, pero que sí vulnera los principios y valores de un sistema tributario" (p 409). Asimismo, Jesús Ramos (2014) manifestó que dicho término debe de ser entendido como la "actividad de un sujeto direccionada a eliminar, reducir o diferir la obligación tributaria mediante figuras, negocios, contratos o actos que, en principio, son perfectamente legales y se llevan a cabo en la realidad de los hechos" ( $\mathrm{p} 2$ ).

En definitiva, mediante la elusión fiscal se busca evitar total o parcialmente la carga fiscal de las actividades económicas realizadas por los sujetos pasivos de la obligación tributaria, mediante un abuso deliberado de la legislación tributaria nacional e internacional, empleando para ello en principio estructuras válidas con el único fin de obtener un ahorro fiscal.

Por su parte, es preciso indicar que la elusión fiscal internacional no implica que los sujetos pasivos busquen la aplicación de un sistema fiscal que se caracterice por la ausencia de normas que graven las rentas obtenidas, sino que puede incluir la búsqueda de países que prevean legislaciones o regímenes preferenciales o incluso cuyas políticas fiscales se encuentren orientadas a establecer una tributación moderada.

Para Xavier (2005) el fenómeno de la elusión fiscal internacional se asienta en un doble presupuesto:

La existencia de dos o más ordenamientos tributarios, de los cuales uno o más de uno se presentan, frente a una situación concreta, como más favorable que el otro 
u otros; y la facultad de opción o selección voluntaria por el contribuyen del ordenamiento tributario aplicable, por la influencia voluntaria en la producción del hecho o hechos generadores en términos de atraer la respectiva aplicación. (p. 246 a 248).

Es por esta razón que José Prieto (1995) mencionó que “en los supuestos de elusión fiscal internacional se afecta el principio de justicia tributaria, pero no en relación con sujetos sino con las finanzas de los diferentes Estados, ya que lo no percibido por uno será un ingreso para otro"'(p 125)

En síntesis, lo que caracteriza a la elusión fiscal internacional es la posibilidad que tienen las empresas multinacionales de realizar estrategias en las cuales se apliquen los ordenamientos jurídicos tributarios más favorables, siendo que para ello se aprovechan de los vacíos legales, incoherencias, acuerdos internacionales o trasladan los beneficios empresariales a determinados territorios, a fin de aplicar el elemento de conexión previsto en la legislación de ese país, con el único objetivo de reducir al máximo el pago de tributos.

Las modalidades de elusión fiscal internacional pueden clasificarse en función de la naturaleza del elemento de conexión utilizado, es decir, en elusión fiscal objetiva o subjetiva.

\subsubsection{Elusión fiscal subjetiva}

La elusión fiscal subjetiva opera a través de los elementos de conexión subjetivos, tales como residencia o domicilio del sujeto pasivo.

Este tipo de elusión se produce en el caso de un contribuyente que para evitar la aplicación de la tasa del impuesto dispuesta por el país donde reside, decide trasladar su domicilio hacia una jurisdicción con menor tributación. Un ejemplo sería la expatriación fiscal del domicilio de un país con tasas impositivas altas hacia Suiza, a fin de beneficiarse del régimen especial previsto para los domiciliados; por lo que estaríamos ante un caso en el que se emplea el domicilio fiscal con el propósito exclusivo de que se aplique un régimen tributario más favorable.

Ahora bien, en algunas ocasiones, los contribuyentes (persona natural o jurídica) establecen su domicilio fiscal en aquellos estados que mantienen diversos convenios para 
evitar la doble imposición, los cuales solo se aplican a los residentes de los estados contratantes, o en su defecto constituyen empresas intermediarias las cuales se ubican en aquellas jurisdicciones, para de esta manera beneficiarse de las disposiciones previstas en los mencionados convenios; no obstante, esta práctica puede encontrarse inmersa en el denominado treaty shopping, el cual desarrollaremos más adelante.

En síntesis, mediante este tipo de elusión lo que se busca es disminuir la carga fiscal que en principio le correspondería pagar a los contribuyentes, mediante la modificación del domicilio de la empresa o la residencia de la persona natural a las que se les atribuye las rentas generadas por sus actividades empresariales.

\subsubsection{Elusión fiscal objetiva}

La elusión fiscal objetiva se concreta a través de la aplicación de los criterios de conexión objetivos, fundamentalmente, vinculado a la fuente de producción de la renta, siendo que en este caso lo que se busca es que dicho rendimiento se lleve a cabo, total o parcialmente, en un territorio que establezca un régimen tributario favorable. Según Alberto Xavier (2005), este tipo de elusión puede clasificarse de la siguiente manera:

La elusión fiscal objetiva puede clasificarse en varias especies, de acuerdo al objetivo del contribuyente para influenciar el elemento de conexión en referencia: dividir la renta, distribuyéndola entre territorios fiscales distintos; acumular la renta en territorio fiscalmente favorable, o transferir la renta de uno hacia otro ordenamiento menos oneroso (p. 282)

En ese sentido, la división de la renta que se lleva a cabo en este tipo de elusión tributaria, tiene en cuenta los elementos de conexión que permite su imputación a diversos territorios, elementos de conexión sin las cuales tales rentas serían imputadas a un único ordenamiento.

Un ejemplo de este tipo de elusión se da en el llamado sistema de Split-payroll, por el cual las remuneraciones de los gerentes que laboran para un grupo empresarial, en vez de ser pagados por la matriz, para la cual prestan efectivamente el servicio, son pagados por las subsidiarias y sucursales instaladas en otros países, de esta manera se reduce el impacto tributario no solo en cabeza de los gerentes, sino que también dicho sistema otorga la posibilidad de aumentar los gastos deducibles por tal hecho. 
Ahora bien, existen otras modalidades que son empleadas en el planeamiento utilizado por las empresas multinacionales, las cuales pasaremos a analizar a continuación.

\subsection{Instrumentos de la elusión fiscal internacional}

Existen diferentes mecanismos empleados por las empresas con el único objetivo de reducir el monto sujeto a gravamen de manera artificiosa; sin embargo, dado que nuestro objeto de estudio es el régimen del Patent Box, analizaremos cómo las empresas podrían emplear tales mecanismos, en combinación con dicho régimen, y cómo estas ocasionarían un perjuicio al estado peruano, y qué soluciones se podría llevar a cabo para evitar dicha situación.

\subsubsection{El Patent Box y los Precios de Transferencia}

Los precios de transferencia deben de ser entendidos como el valor o precio pactados en las transacciones realizadas entre partes vinculadas, esto es, entre aquellas sociedades que se encuentran sometidas al mismo poder de decisión, para Hernández y Justo (2012) dicho concepto debe de ser entendido de la siguiente manera:

El precio de transferencia, dentro del marketing empresarial, es el precio que pactan dos empresas que pertenecen a un mismo grupo empresarial o a una misma persona. Mediante este precio se transfieren mercancías, servicios, beneficios, etc. entre ambas empresas. Una le puede vender a la otra a un precio diferente al de mercado, superior o inferior a dicho precio. Esto indica que el precio de transferencia no sigue las reglas de una economía de mercado, es decir no siempre se regula mediante la oferta y la demanda. ( $p$ $1)$.

Es por ese motivo que puede existir una manipulación en los precios de los bienes, servicios $\mathrm{u}$ otras operaciones que se realicen entre empresas del mismo grupo, ya sea sobrevalorando o subvaluando de manera artificial el valor de tales prestaciones, por lo que a fin de contrarrestar dicha situación se implementó el principio de libre concurrencia o arm's length, mediante el cual se establece como criterio objetivo que las referidas transacciones se pacten en las mismas condiciones que se harían con un tercero no vinculado, esto es, en condiciones de mercado normales; sin embargo, a pesar de tal disposición, algunas empresas multinacionales suscriben contratos con sus filiales en las 
que alteran el precio real de los bienes o servicios comerciales, y de esa manera erosionar la base imponible sujeta a gravamen.

Por ejemplo, en el año 2013, las empresas Glencore y Xstrata, luego de quince meses de negociaciones y de la aprobación de los organismos regulatorios de diversos países de la Unión Europea y China, se fusionaron y de esa manera pasó a ser la cuarta compañía minera más importante a nivel internacional; sin embargo, en los últimos años se ha visto envuelta en acusaciones de evasión y defraudación tributaria. Al parecer el consorcio se aprovechó de los vacíos legales existentes en los sistemas fiscales de los países donde se encuentran ubicadas sus filiales; así como, de su compleja estructura global para evadir el pago de impuestos.

Uno de los mecanismos empleados fue el de los precios de transferencia en las exportaciones e importaciones que se efectuaron dentro de las empresas pertenecientes al grupo. En el caso de las exportaciones, se advirtió que el consorcio comercializó las materias primas a un precio inferior al del mercado; mientras que en las importaciones de maquinarias, el precio empleado fue demasiado alto, de tal manera que las ganancias fueron menores o incluso se obtuvieron pérdidas, evitándose de esta manera el pago de impuestos en el país donde se llevaron a cabo las actividades de extracción de materias primas.

Dicha situación también fue advertida en el Perú, tal es así que el sindicato de trabajadores mineros de la Empresa Los Quenuales S.A. denunció a dicha subsidiaria, perteneciente a la multinacional Glencore, por evasión tributaria, debido a que los precios de venta de los metales exportados fueron efectuados a un precio por debajo del valor de mercado, reduciendo de esta manera el pago de impuestos en el territorio peruano, dicha denuncia se sustentó en la comparación de los estados financieros de la citada empresa con otra perteneciente al mismo grupo (Peru Bar S.A.), obteniéndose el siguiente resultado:

El sindicato miró las cifras minuciosamente y descubrió algo sorprendente: en la planta Los Quenuales los ingresos operativos habían bajado de 371 millones de dólares americanos (2007) a 155 millones, en el año 2008, lo que significa que ascendían apenas al 42\% de los ingresos del año anterior. En ese año, Los Quenuales logró un precio de venta promedio de 250 dólares americanos por tonelada de zinc, y en el tercer trimestre, de solo 160 dólares americanos. La filial de Glencore, Perubar declaró por su parte un 
precio de venta promedio de 360 dólares americanos por tonelada, $44 \%$ más alto que el de Los Quenuales (p. 77).

Si bien este caso no se vincula con la aplicación del régimen del Patent Box, ayuda a darnos cuenta que la utilización de los precios de transferencia en las transacciones ocurridas dentro de los grupos empresariales podrían generar perjuicios a la recaudación tributaria del país en donde se lleve a cabo las actividades de $\mathrm{I}+\mathrm{D}+\mathrm{i}$, por cuanto las cesiones de los activos de propiedad intelectual podrían realizarse a un precio menor que al que le correspondería, reduciendo de esta manera la base imponible a la cual se le aplicaría la tasa prevista en el régimen del Patent Box, generando de esta manera un perjuicio a las arcas del estado peruano.

\subsubsection{EI Patente Box y el treaty shopping}

Como consecuencia de la expansión de actividades en distintos territorios, los estados empezaron a suscribir diversos tratados internacionales a fin de posibilitar el intercambio entre los mismos, creando condiciones favorables para la circulación de bienes, servicios, entre otros, fuera de sus fronteras.

A su vez, los estados recurrieron a convenios internacionales con el propósito de evitar una doble carga negativa sobre la actividad de los particulares, por cuanto se advirtió que algunas operaciones realizadas por un mismo sujeto pasivo se encontraban afectas a más de un régimen tributario, reduciendo de esa manera los beneficios empresariales obtenidos, y a su vez influenciaba en la decisión de las empresas de invertir en ciertos territorios.

Es por ello que los comentarios del artículo 1 el Modelo de Convenio de la OCDE se manifestó que "los convenios tienen como finalidad evitar la doble imposición, promover los intercambios de bienes y servicios; así como, los movimientos de capitales, mediante la eliminación de la doble imposición internacional” (p 48)

Si bien los convenios para evitar la doble imposición pueden ser muy útiles en operaciones de planificación fiscal internacional, en ocasiones tales convenios pueden ser empleados con el único objetivo de reducir la carga tributaria de manera artificiosa, es decir, el denominado treaty shopping, tal es así que Félix Vega Borrego (2003) indicó lo siguiente: 
Las estructuras treaty shopping permiten reducir la carga tributaria global combinando la reducción de la tributación en la fuente prevista en el convenio de doble imposición con un régimen tributario favorable en el Estado de residencia de la sociedad intermedia o conductora. (p 71)

En ese sentido, el objetivo consiste en eliminar o reducir la tributación en el estado en que se ha generado la renta (estado de la fuente) a través de la utilización de un convenio de doble imposición. Para Acosta, Bruzzone y Nieves (2013) el Treaty Shopping puede ser considerado de la siguiente forma:

Se trata de conductas que son consecuencia de una planificación tributaria que rebasa los límites legales atribuidos a la economía de opción, llevando así a un uso impropio de tratados que implica, o bien el amparo a un CDI por una persona que no tendría derecho a ello, o bien la calificación inadecuada en el marco de un CDI de las circunstancias fácticas involucradas. ( $\mathrm{p} 2$ )

En otras palabras estamos ante un abuso de los convenios para evitar la doble imposición suscritos por los estados, por cuanto se les aplica los beneficios que en principio no les correspondería, para ello se emplean diversos mecanismos, por ejemplo algunas empresas multinacionales buscan constituir una empresa intermediaria o las denominadas “conduit companies", la cual si bien será la que obtenga los beneficios empresariales en el estado de la fuente, tales rentas no permanecerán en dicha empresa, sino que serán transferidas a aquella que constituyó dicha intermediaria, quien sería el verdadero beneficiario efectivo de las utilidades.

En consecuencia, si tenemos en cuenta los beneficios fiscales que prevé el Patent Box, podría ocurrir que las empresas multinacionales, mediante un planeamiento tributario agresivo, establezca filiales en aquellos territorios que cuenten con una red de convenios que les permita eludir el pago de los impuestos que les correspondería.

\subsubsection{El Patent Box y los paraísos fiscales}

Si bien no se ha dispuesto una definición oficial de lo que debe de entenderse por un paraíso fiscal, este podría ser conceptualizado como aquel país, región o territorio que prevé una sistema tributario muy favorable para las operaciones económicas que se realicen en tales lugares, siendo que en ocasiones la presión tributaria previstas en sus jurisdicciones resulta ser demasiado baja o casi inexistente, esta posición también es 
compartida por Martha Ochoa (2014), quien manifestó que los paraísos fiscales pueden ser definidos como:

aquellas jurisdicciones, de carácter estatal o subestatal, con niveles de tributación bajos o inexistentes, en los que los operadores económicos gozan del anonimato que proporcionan el secreto bancario, mercantil y profesional, garantizados estos últimos por normas de rango legal o constitucional. La combinación de estos elementos, tributación privilegiada y opacidad, nos permiten configurar un concepto de paraíso coincidente con la traducción literal de su denominación en inglés (tax haven) que se traduce como "puerto o refugio fiscal" (p 7).

Por su parte, el Diccionario contable, Administrativo, Fiscal de José Isauro López (2004) lo define como "jurisdicciones que dentro de su administración tributaria no contemplan normas que regulen la generación de un impuesto sobre el ingreso o lo hacen a tasas mínimas o simbólicas, en relación con otros sistemas de Administración Tributaria.” ( $p$ 278). Esta misma definición es seguida por José Chiarella Privette (2003), quien señala que un paraíso fiscal

Estaría constituido por cualquier país o territorio en donde el movimiento de personas o bienes hacia su jurisdicción o la inclusión en una transacción internacional de una entidad constituida o administrada en el mismo, tiene como resultado una afectación tributaria neutra o una disminución de la que resultaría de otro modo aplicable (p 261 a 264).

Como vemos, la referencia a los paraísos fiscales debe de ser entendida como aquellos Estados que ofrecen sistemas fiscales más ventajosos en comparación con otros, es decir, estamos ante territorios que ofrecen un régimen fiscal privilegiado; dado que, las tasas aplicables a las rentas o ingresos gravados son muy bajas o, incluso, no aplican una tasa, lo que al final constituye un eficaz incentivo para atraer a empresas e inversores del exterior; además que constituye un instrumento que facilita la elusión fiscal de contribuyentes pertenecientes a otras jurisdicciones.

Es por estas razones que tanto las personas naturales como las jurídicas utilizan los paraísos fiscales para escapar de la obligación de contribuir en los territorios que poseen una tasa más alta en comparación con tales lugares, empleando para ello las denomindas "off-shore", por lo que su utilización podrá ser legítima o ilegítima, dependiendo del tipo de planeamiento que se lleve a cabo. Un ejemplo de la utilización de los paraísos fiscales, son los denominado Doble Irlandés o Sandwich Holandés. 
Esta estructura consiste en crear un grupo de 4 sociedades situadas en Irlanda y un paraíso fiscal (por ejemplo, Islas Bermudas), y en Holana y otro paraíso (por ejemplo, Antillas Holandesas). La sociedad de Irlanda, que es la que recibe los ingresos de todo el mundo, para cantidades astronómicas a la situada en el primer paraíso por la utilización de los derechos intelectuales. Para no pagar impuesto en Irlanda por los beneficios que queda, se envían a la sociedad de Holanda, aprovechando que por estas operaciones tampoco pagan impuestos [debido al convenido que tienen suscritos ambos países], y de ahí se envían finalmente al segundo paraíso, pagando un impuesto irrisorio. El resultado final es que la totalidad del dinero se ha situado en los dos paraísos fiscales, sin haber pagado ningún impuesto. (Pelaez Martos, 2014, párrafos 5 y 6).

En consecuencia, este tipo de planeamiento fiscal agresivo puede ser replicado en nuestro territorio en caso optemos por la implementación del régimen del Patent Box; sin embargo, ante dicha situación se debe de tener en cuenta las directrices establecidos en el Proyecto BEPS y que nos ayudarían a contrarrestar los efectos negativos de los mencionados planeamientos.

\subsection{Medidas Antielusivas - Proyecto BEPS}

Como estamos frente a activos móviles fácilmente transferibles y teniendo en cuenta que una de las consecuencias de la globalización es la integración de las economías, pues es usual que las empresas, a fin de reducir su carga fiscal, transfieran los beneficios obtenidos de la explotación de los activos intangibles de propiedad intelectual a aquellas jurisdicciones que hayan establecido tasas reducidas o mayores incentivos fiscales; no obstante, este tipo de planeamiento tributario suele sustentarse en prácticas perniciosas que solo se encuentran orientadas a transferir artificialmente los mencionados beneficios o erosionar la base imponible, afectando la recaudación del país en el cual se llevó a cabo la actividad económica del referido activo.

Ante esta situación, la Organización para la Cooperación y el Desarrollo Económicos (OCDE), desarrollo el Plan BEPS, el cual surge por iniciativa de las principales economías del mundo, esto es, el denominado G20, y que tiene como objetivo principal establecer directrices que sirvan de sustento a los sistemas fiscales de los países para que estos puedan combatir los planeamientos fiscales perniciosos, en otras palabras, se busca contrarrestar las estructuras internacionales empleadas por las empresas 
multinacionales con el único objetivo de erosionar sus bases imponibles o mediante el traslado de beneficios hacia territorios de baja o nula imposición.

Ahora bien, el 5 de octubre de 2015 se publicaron los reportes finales sobre las recomendaciones de la OCDE, estableciéndose 15 acciones, las cuales según Jesús Ramos (2015) "tiene por objeto brindar coherencia, transparencia y sustancia al sistema fiscal internacional a fin de eliminar los defectos y desajustes normativos que permiten a las empresas multinacionales estructurar estrategias de planificación fiscal agresiva" (p 376).

Dentro de las medidas previstas en el Plan BEPS, tenemos a la acción 5 titulada "Combatir las prácticas tributarias perniciosas, teniendo en cuenta la transparencia y la sustancia", la cual centra su objeto de estudio en dos ámbitos de estudio que han generado últimamente preocupación dentro de la comunidad internacional:

i) Los regímenes fiscales preferenciales, es decir, aquellos que ofrecen incentivos fiscales para aquellas empresas que desarrollen cierto tipo de actividades económicas, en ese sentido estamos ante regímenes que establecen tasas reducidas o exenciones, por lo que promueven la deslocalización de los beneficios hacia dichas jurisdicciones.

ii) Los Tax ruling (Acuerdos entre contribuyentes específicos y las Administraciones tributarias), los cuales podrían generar efectos negativos dentro a nivel internacional.

Básicamente, lo que se busca mediante la acción 5 es disponer que la empresa que va a gozar del regimen preferencial sea la que efectivamente realice la actividad de I + D + I, es decir, que haya una actividad sustantiva, siendo para ello necesario la colaboración de las administracions tributarias de otras jurisdicciones, a fin de determiner si se cumple con el principio del nexus approach. 


\section{CONCLUSIONES}

- Solo el avance en las áreas del conocimiento cientifico y la tecnología nos brindará la oportunidad de obtener un desarrollo económico sostenible, por lo que es indispensable que se implemente politicas publicas dirigidas a la promoción de proyectos científicos.

- Sin embargo, el gasto total que desembolsa el estado para fomentar las actividades de investigación, desarrollo e innovación es realmente bajo, por lo que tenemos que acudir a otras herramientas que permitar fomentar tales actividades.

- El patent box constituye una buena alternativa para incrementar las referidas actividades de $\mathrm{I}+\mathrm{d}+\mathrm{i}$; además que, permitirá que las empresas nacionales puedan competir con las empresas extranjeras, mejorando de esta manera su rentabilidad.

- Si bien nuestra legislación prevé disposiciones relacionadas a la deducción de los gastos vinculados a las actividades de investigación, desarrollo e innovación, estas resultan poco atractivas para el sector empresarial, por lo que el establecer un régimen preferencial para las ganancias obtenidas de la comercialización de los activos de propiedad intelectual, podría traer como consecuencia, que las empresas se sientan motivadas a invertir en dichas actividades a fin de mejorar su productividad.

- Una de las desventajas que podría generar este régimen, es que las empresas utilicen diversas estructuras a fin de transferir sus beneficios hacia jurisdicciones en las cuales erosionarían la base imponible.

- En definitiva, existen diversos motivos que fundamentan la implementación del regimen del paten box dentro de nuestro sistema fiscal, por cuanto podría generar un mayor desarrollo economico sustentado en los avances que se podrían obtener a través de los proyectos de investigación vinculados a nuestros recursos naturales, siendo que solo nos correspondería limitar dicho regimen a fin de que no sea utilizado con el único objetivo de eludir el pago de impuestos. 


\section{REFERENCIAS}

Acosta N., Bruzzone L. y Nieves G. (2013). El abuso de los convenios. Recuperado de http://www.ccea.org.uy/ccea_nws04/docs/El+abuso+de+convenios+Modalidade $\underline{\mathrm{s}+\mathrm{y}+\text { forma+de+evitarlo+desde+la+perspectiva+uruguaya+- }}$ + Natalia+Acosta\%252C+Leonardo+Bruzzone+y+Guillermo+Nieves+\%E2\%80 \%93+DGI.pdf

Adonnino, P. (2003). La planificación fiscal Internacional. Bogotá: Editorial Temis.

Borlaug Norman (s.f). https://www.isaaa.org/kc/cropbiotechupdate/tribute/borlaug/Norman\%20Borlau g-Tribute-Spanish.pdf

Bustillo, A. (23 de enero de 2014). Patent Box', un incentivo fiscal que premia tu innovación. Recuperado de http://www.expansion.com/2014/01/23/emprendedoresempleo/emprendimiento/1390501814.html

Cabello A. y Ortiz E. (2013). Políticas públicas de innovación tecnológica y desarrollo: teoría y propuesta de educación superior. Convergencia Revista de Ciencias Sociales, (61), 135-172. Recuperado de http://www.redalyc.org/pdf/105/10524674008.pdf

Conoce las cifras de la Investigación y el Desarrollo en el Perú (19 de mayo de 2017). La República. Recuperado de http://larepublica.pe/economia/877517-conocelas-cifras-de-la-investigacion-y-el-desarrollo-en-el-peru

Constitución Política del Perú de 1993 (30 de diciembre de 1993) Recuperado del sitio de internet del Sistema Peruano de Información Jurídica: http://spij.minjus.gob.pe/web/main.asp

Chiarella Privtte, J. (2013). Jurisdicciones Tributarias en Latinoamérica y localización de sociedades holding: análisis del caso peruano. Análisis Tributario, (309), 2328.

Decreto Legislativo N. ${ }^{\circ} 1124$. Decreto Legislativo que modifica la Ley del Impuesto a la Renta. (23 de julio de 2012). Recuperado del sitio de internet del Sistema Peruano de Información Jurídica: http://spij.minjus.gob.pe/web/main.asp

Decreto Supremo N²20-2015-EF. Decreto Supremo que modifica el Reglamento de la Ley del Impuesto a la Renta aprobado por Decreto Supremo N ${ }^{\circ} 122-94-E F$ y normas modificatorias (31 de julio de 2015). Recuperado del sitio de internet del Sistema Peruano de Información Jurídica: http://spij.minjus.gob.pe/web/main.asp 
Decreto Supremo N ${ }^{\circ}$ 179-2004-EF. Texto Único Ordenado de la Ley del Impuesto a la Renta (8 de diciembre de 2004). Recuperado del sitio de internet del Sistema Peruano de Información Jurídica: http://spij.minjus.gob.pe/web/main.asp

Estratetegia de Lisboa (2000) Recuperado de http://www.idi.mineco.gob.es/stfls/MICINN/Internacional/FICHEROS/Estrategi a_de_Lisboa_y_Proceso_de_Liubliana.pdf

Fdez Soutullo, D. (23 de diciembre de 2015). La reforma fiscal 2016: incentivos fiscales. Patent Box. Recuperado de http://www.ticlegal.com/reforma$\underline{\text { fiscal2016/ }}$

Flores J, Ly M., Tapia N. y Maldonado H. (s.f). Bioremediación de metales tóxicos en efluentes mineros aplicando biosorción. Recuperado de http://revistasinvestigacion.unmsm.edu.pe/index.php/iigeo/article/viewFile/4651 $\underline{13730}$

García Guzmán M. (2011). Políticas de innovación científica y tecnológica en América Latina. Revista Electrónica del Centro de Estudios en Administración Pública de la Facultad de Ciencias Políticas y Sociales, (7), 1-11 Recuperado de http://www.politicascti.net/index.php?option=com_docman\&task=doc_view\&gi $\underline{\mathrm{d}=72 \& \text { Itemid }=36 \& \text { lang }=\mathrm{pt}}$

García Novoa, C. (2005) Reflexiones sobre las medidas para combatir la elusión fiscal. Cláusulas generales y especiales. Vectigalia. (1), $118-125$.

Gil García, E. (2014). Los incentivos fiscales a la investigación a la luz de la reforma tributaria: la deducción por actividades de investigación, desarrollo e innovación y el régimen del patent box. Instituto de Estudios Fiscales, (10), 111 - 118. Recuperado de https://rua.ua.es/dspace/bitstream/10045/50087/1/2015_GilGarcia_Documentos-IEF.pdf

Gil García, E. (2016). El impacto de BEPS en el régimen español de patent box. Revista Quincena Fiscal, (9), Recuperado de http://www.asesoriayempresas.es/articulo/JURIDICO/233138/el-impacto-debeps-en-el-regimen-espanol-de-patent-box

Hernández Vásquez, O. y Justo Alonso, Á. (2012). Precios de Transferencia. Recuperado de http://www.ief.es/documentos/recursos/publicaciones/revistas/cuadernos_forma cion/2012_15_8.pdf

Lalanne, G. (2005). Economía de opción y fraude de ley en el Derecho Tributario. Revista del Instituto Peruano de Derecho Tributario. Lima, Instituto Peruano de Derecho Tributario (44) p. 111.

Ley $\mathrm{N}^{\circ}$ 28303. Ley Marco de Ciencia, Tecnología e Innovación Tecnológica. (23 de julio de 2004). Recuperado del sitio de internet del Sistema Peruano de Información Jurídica: http://spij.minjus.gob.pe/web/main.asp

Ley $\mathrm{N}^{\circ}$ 30056. Ley que modifica diversas leyes para facilitar la inversión, impulsar el desarrollo productivo y el crecimiento empresarial ( 2 de julio de 2013). 
Recuperado del sitio de internet del Sistema Peruano de Información Jurídica: http://spij.minjus.gob.pe/web/main.asp

Ley $\mathrm{N}^{\circ}$ 30309. Ley que promueve la investigación científica, desarrollo tecnológico e innovación tecnológica (13 de marzo de 2015). Recuperado del sitio de internet del Sistema Peruano de Información Jurídica:

http://spij.minjus.gob.pe/web/main.asp

Ley 165, Convención para la Diversidad Biológica de las Naciones Unidas (1994). Recuperado de http://www.humboldt.org.co/images/documentos/pdf/Normativo/1994-ley1651994.pdf

Liu R., Sotelo E. y Zuzunaga F. (2012). Norma XVI: Calificación, elusión de normas tributarias y simulación. Revista Ius et veritas, (45), 396-419, Recuperado de http://revistas.pucp.edu.pe/index.php/iusetveritas/article/viewFile/12012/12580

López López, J. (2001). Diccionario Contable, Administrativo, fiscal (2004). México: Thomson Paraninf.

Marin Anabel (2017) La Innovación y la Tecnología: ¿Una ruta hacia el desarrollo?. Recuperado de http://www.festransformacion.org/fileadmin/Documentos_Pagina/Actividades/Conferencias_In ternacionales/2016_Desarollo_Estado_Politica_Industrial/Relatorias/P5_160802 Innovacion_y tecnologia.pdf

Ochoa León, M. (2013). Elusión o Evasión Fiscal. Recuperado de https://dialnet.unirioja.es/descarga/articulo/5063717.pdf

OCDE (2010). Modelo de Convenio Tributario sobre la renta y sobre el patrimonio. Recuperado de http://www.gerens.cl/gerens/ModeloConvenioTributario.pdf

Organización de Estados Iberoamericanos para la Educación, la Ciencia y la Cultura (2014). Ciencia, Tecnología e innovación para el desarrollo y la cohesión social. Recuperado de www.oei.es/historico/cti2021.pdf

Organización de las Naciones Unidas para la Educación, la Ciencia y la Cultura (2010). Informe de la Unesco sobre la ciencia 2010. Recuperado de http://unesdoc.unesco.org/images/0018/001898/189883s.pdf

Pistone, Pasquale (2014). Coordinating the Action of Regional and Global Players during the Shift from Bilateralism to Multilateralism in International Tax Law. World Tax Journal, (6), Recuperado de http://www.webicdt.net:8080/sitios/principal/centrodeinvestigacion/Lists/Artcul os\%20Revistas/Attachments/31/PASQUALE\%20PISTONE.pdf

Prieto Jano, J. (1995). La planificación fiscal internacional y en el ámbito de la Unión Europea. La elusión fiscal. Recuperado de http://uvadoc.uva.es/bitstream/10324/3006/1/PlanificacionFiscal.pdf

Ramos Ángeles, J. (2014). La elusión tributaria y la economía de opción. A propósito de la suspensión de la facultad de SUNAT para aplicar la Norma XVI del Título 
Preliminar del Código Tributario. Informativo Caballero Bustamante, (788), 16. Recuperado de http://www.academia.edu/7676831/La_elusi\%C3\%B3n_fiscal_y_la_econom\%C 3\%ADa_de_opci\%C3\%B3n_A_prop\%C3\%B3sito_de la_suspensi\%C3\%B3n de_la_facultad_de_SUNAT_para_aplicar_la_Norma_XVI_del_T\%C3\%ADtulo _Preliminar_del_C\%C3\%B3digo_Tributario

Rosas, J. y Mares C. (2016). Nuevo Régimen Tributario aplicable a los gastos en investigación, desarrollo e innovación $(\mathrm{I}+\mathrm{D}+\mathrm{i})$. Apuntes sobre su alcance y aplicación. Revista del Instituto Peruano de Derecho Tributario, 60, 11-34. Recuperado de http://www.ipdt.org/uploads/docs/01_Rev60_JRCH-CMR.pdf

Valdiviezo C. (31 de octubre de 2016). Concytec y beneficios tributarios: falta claridad en incentivos para la innovación. Recuperado de http://semanaeconomica.com/article/legal-y-politica/marco-legal/203172-faltaclaridad-en-los-incentivos-para-innovacion/

Vega, B. F. A., Eucotax., \& Instituto de Estudios Fiscales. (2006). Limitation on benefits clauses in double taxation conventions. The Hague [etc.: Kluwer Law International.

Xavier, A., \& Universidad Austral (Buenos Aires). (2005). Derecho tributario internacional: Conceptos fundamentales. Buenos Aires: Editorial Ábaco de Rodolfo Depalma. 


\section{BIBLIOGRAFÍA}

Bravo Cucci, J. (2006). La elusión, el fraude a la ley tributaria y el segundo párrafo de la Norma VIII del Título Preliminar del Código Tributario. Revista del Instituto Peruano de Derecho Tributario, (44), 143-153. Recuperado de http://www.ipdt.org/editor/docs/04_Rev44_JBC.pdf

García Schreck, M. (2005). Precios de Transferencia, apuntes sobre el concepto de vinculación en el Perú. Análisis Tributario, XVIII(215), 17-22.

Villanueva Gutiérrez, W (2002). La regla de valor de mercado, los precios de transferencia y la subcapitalización. Análisis Tributario, XV(168), 28-31.

Wittendorf, J. (2011). The Arm's-Length Principle and Fair Value: Identical Twin or Just Close Relatives? Tax Notes International, (18), 223-249. Recuperado de http://corit-academic.org/wp-content/uploads/2011/12/62TI0223-4.pdf 